\title{
Unravelling the molecular control of calvarial suture fusion in children with craniosynostosis
}

\author{
Anna K Coussens ${ }^{1,2}$, Christopher R Wilkinson ${ }^{2,3}$, Ian P Hughes ${ }^{1}$, C \\ Phillip Morris ${ }^{1}$, Angela van Daal ${ }^{\dagger 1,6}$, Peter J Anderson ${ }^{\dagger 2,4,5}$ and \\ Barry C Powell* $+2,4$
}

\begin{abstract}
Address: ${ }^{1}$ Cooperative Research Centre for Diagnostics, Institute of Health and Biomedical Innovation, Queensland University of Technology, Brisbane 4001, Australia, ${ }^{2}$ Women's and Children's Health Research Institute, Adelaide 5006, Australia, ${ }^{3}$ Faculty of Engineering, Computer \& Mathematical Sciences, University of Adelaide, Adelaide 5005, Australia, ${ }^{4}$ Faculty of Health Sciences, University of Adelaide, Adelaide 5005, Australia, ${ }^{5}$ Australian Craniofacial Unit, Adelaide 5006, Australia and ${ }^{6}$ Faculty of Health Sciences and Medicine, Bond University, Gold Coast 4229, Australia

Email: Anna K Coussens - anna.coussens@gmail.com; Christopher R Wilkinson - christopher.wilkinson@madderns.com.au; Ian P Hughes - carproyals@hotmail.com; C Phillip Morris - p.morris@qut.edu.au; Angela van Daal - avandaal@bond.edu.au; Peter J Anderson - haemro2@hotmail.com; Barry C Powell* - barry.powell@adelaide.edu.au

* Corresponding author †Equal contributors
\end{abstract}

Published: 12 December 2007

BMC Genomics 2007, 8:458 doi:10.1 186/1471-2164-8-458

This article is available from: http://www.biomedcentral.com/I47/-2/64/8/458

(c) 2007 Coussens et al; licensee BioMed Central Ltd.

This is an Open Access article distributed under the terms of the Creative Commons Attribution License (http://creativecommons.org/licenses/by/2.0), which permits unrestricted use, distribution, and reproduction in any medium, provided the original work is properly cited.
Received: II September 2007

Accepted: 12 December 2007

\begin{abstract}
Background: Craniosynostosis, the premature fusion of calvarial sutures, is a common craniofacial abnormality. Causative mutations in more than 10 genes have been identified, involving fibroblast growth factor, transforming growth factor beta, and Eph/ephrin signalling pathways. Mutations affect each human calvarial suture (coronal, sagittal, metopic, and lambdoid) differently, suggesting different gene expression patterns exist in each human suture. To better understand the molecular control of human suture morphogenesis we used microarray analysis to identify genes differentially expressed during suture fusion in children with craniosynostosis. Expression differences were also analysed between each unfused suture type, between sutures from syndromic and non-syndromic craniosynostosis patients, and between unfused sutures from individuals with and without craniosynostosis.
\end{abstract}

Results: We identified genes with increased expression in unfused sutures compared to fusing/ fused sutures that may be pivotal to the maintenance of suture patency or in controlling early osteoblast differentiation (i.e. RBP4, GPC3, CIQTNF3, ILI IRA, PTN, POSTN). In addition, we have identified genes with increased expression in fusing/fused suture tissue that we suggest could have a role in premature suture fusion (i.e. WIFI, ANXA3, CYFIP2). Proteins of two of these genes, glypican 3 and retinol binding protein 4 , were investigated by immunohistochemistry and localised to the suture mesenchyme and osteogenic fronts of developing human calvaria, respectively, suggesting novel roles for these proteins in the maintenance of suture patency or in controlling early osteoblast differentiation. We show that there is limited difference in whole genome expression between sutures isolated from patients with syndromic and non-syndromic craniosynostosis and confirmed this by quantitative RT-PCR. Furthermore, distinct expression profiles for each unfused suture type were noted, with the metopic suture being most disparate. Finally, although calvarial bones are generally thought to grow without a cartilage precursor, we 
show histologically and by identification of cartilage-specific gene expression that cartilage may be involved in the morphogenesis of lambdoid and posterior sagittal sutures.

Conclusion: This study has provided further insight into the complex signalling network which controls human calvarial suture morphogenesis and craniosynostosis. Identified genes are candidates for targeted therapeutic development and to screen for craniosynostosis-causing mutations.

\section{Background}

Calvarial bones form by the proliferation and differentiation of multipotent mesenchymal cells into osteoblasts. This process, known as intramembranous ossification, is distinct from the development of the majority of other bones in the body which form by the ossification of a preexisting cartilaginous matrix (endochondral ossification). Calvaria first form from a condensation of mesenchyme termed the primary centre of ossification. Mesenchymal cell proliferation and subsequent differentiation into osteoblasts occurs at the margins and the bone grows in a radial fashion until the osteogenic fronts of two calvaria approximate each other and structures called sutures form between the bones [1]. These intervening fibrous sutures act as flexible joints between the developing bones allowing the skull to change shape and grow during development. Maintenance of growth at the osteogenic fronts at the edges of the sutures requires a fine balance between proliferation and differentiation. Additionally, apoptosis has a role ensuring that the two osteogenic fronts remain separated [2]. Disruption of any of these processes can result in the premature fusion of calvarial sutures, known as craniosynostosis.

Craniosynostosis is amongst the most common cranial defects, second only to cleft palate. It occurs in 1 in 2500 live births and can be associated with significant morbidity, including mental retardation, deafness, and blindness, in addition to the significant social stigma associated with craniofacial deformation [3]. The condition may be caused by various genetic mutations, exposure to teratogens such as retinoic acid, mechanical stress, or result from certain metabolic or haematologic disorders [4,5]. Non-syndromic craniosynostosis refers to sporadic suture fusion in the absence of other developmental abnormalities and most commonly affects the sagittal suture. Syndromic craniosynostosis occurs as a result of simple genetic mutations and is accompanied by additional developmental abnormalities particularly involving the limbs [6]. Syndromic forms of craniosynostosis commonly affect the coronal suture but other sutures may be affected depending on the underlying genetic mutation. FGFR2 mutations are the most common and most severe affecting the coronal, metopic, sagittal, and lambdoid sutures. FGFR3 mutations affect the coronal and/or metopic sutures. FGFR1, TWIST1 and EFNB1 mutations generally affect only the coronal suture. FNB1 and TGFBR1 mutations have been associated with synostosis of the sagittal and/or lambdoid sutures, while gain-offunction MSX2 mutations result in synostosis of the coronal and sagittal sutures (reviewed in [7]).

The large number of genes identified as causal for craniosynostosis suggests that a complex molecular network controls suture morphogenesis in humans. In addition, rodent studies have revealed a role in suture formation for transforming growth factor beta (TGF $\beta$ ) signalling mediated by various bone morphogenetic proteins (BMPs) [811]. Targeted functional genetic approaches are slowly unravelling the molecular signalling that controls suture morphogenesis. However, there is also a need for a broad experimental approach aimed at identifying all genes and, subsequently, their associated pathways which are essential to suture morphogenesis.

The different phenotypes induced by the known mutations suggest that distinct molecular pathways may be operating in different sutures. This is particularly evident in the case of the metopic suture which, in humans, normally fuses shortly after birth, while the other sutures remain patent until adulthood. This feature of the metopic suture may be explained by the finding in rodents that the frontal suture (equivalent to the metopic suture in humans) is populated by neural crest derived mesenchyme and separates the frontal bones, also of neural crest origin, while the other sutures are a juxtaposition of neural crest and paraxial mesoderm [12-14]. To understand the mechanisms of the fusion process gene expression profiles between the fusing posterior frontal sutures in mice have been compared to profiles from unfused sagittal and coronal sutures [15-20]. However, given that the signalling pathways controlling suture fusion are likely to differ in sutures derived from different developmental origins, it is unclear what such comparisons tell us about these fusion processes. There is, therefore, a need to study differential gene expression between fused and unfused sutures of the same developmental origin.

Subtle differences in cranial biology also exist between rodents and humans. For example, the rodent model created for the Pro250Arg FGFR1 mutation, which causes Pfeiffer syndrome, develops synostosis of the frontal, sag- 
ittal and coronal sutures [21] whereas in humans this mutation commonly affects only the coronal suture. Furthermore, primary cells cultured from patients with FGFR2 mutations and mice generated with the same mutations show differing proliferation and differentiation characteristics (reviewed in [22]). These differences emphasise that mechanisms controlling rodent suture morphogenesis do not exactly mimic those occurring in human sutures.

In this study we have analysed global in vivo expression differences between fused, fusing, and unfused sutures from patients with craniosynostosis to identify genes which are involved in maintaining suture patency and driving suture fusion within each human suture.

\section{Results}

Five patients were recruited to the gene identification stage of this study, one diagnosed with syndromic craniosynostosis (Apert syndrome [MIM 101200]) and four with non-syndromic craniosynostosis (Table 1). Sixteen suture samples were obtained from these patients for microarray analysis; nine from unfused sutures, two from fusing, and five from fused sutures (Fig. 1A). To minimise any age-related changes and to eliminate any sex-related effects on the development of craniosynostosis, sutures were obtained from males aged 3-7 months. The stage of fusion was confirmed by 3D computer tomography (CT), MicroCT, and histological analysis and classified as unfused, fusing, or fused (Fig. 1). We performed microarray analyses on RNA isolated from sutures resected at surgery using the Affymetrix Human U133A 2.0 GeneChip platform containing 18,000 gene transcripts. Microarray data were initially assessed using a number of quality control measures (Additional files 1, 2, 3). RNA digestion plots indicated that all samples showed a high similarity in RNA quality except for one unfused sagittal sample from patient \#36 (US36). NUSE and Mbox plots indicated that this sample had a similar expression intensity compared to other samples but had elevated standard errors. We were initially cautious in our interpretation of any particular difference in expression seen with this sample.

\section{Patient genetic background does not adversely affect gene expression}

Hierarchical clustering, based on whole genome expression, showed samples typically grouped according to stage of fusion or suture type, and not solely by patient of origin, indicating no adverse patient-specific genetic background biases existed (Additional file 4). Importantly, sutures from the Apert syndrome patient grouped more closely with similar sutures from other non-syndromic patients, than they did to each other. These similarities in gene expression between syndromic and non-syndromic patients were confirmed with additional syndromic sam- ples using realtime quantitative RT-PCR (qRT-PCR), as described later. This indicates that patient genetic background does not overly impact on gene expression and it provides proof of principle that the combined analysis of syndromic and non-syndromic patient samples can be applied in the study of general mechanisms of craniosynostosis.

\section{Metopic sutures have different gene expression profiles to other sutures}

The neural crest origin of the metopic suture mesenchyme, compared to the predominantly mesodermal origin of the other sutures may result in the metopic suture, exhibiting significantly different expression profiles to the other suture types. We therefore initially analysed differential gene expression between fused and unfused sutures treating metopic sutures separately. Microarray expression data were combined for all unfused $(n=8)$ and all fusing/ fused $(n=6)$ sutures, from the sagittal, coronal and lambdoid sutures and differential expression was analysed between the two groups. Initially, a subset of differentially expressed probe sets was selected based on those with a multiple testing corrected $P<0.1(\mathrm{n}=84)$ in order to assess how well the analysis separated the two groups of interest. This minimally-selective P-value was chosen to remove a large number of those genes which were not modulated in the two tissue types. Pair-wise correlation of all samples to an arbitrarily chosen unfused suture sample (\#36 non-syndromic, unfused coronal) showed that samples were separated based on stage of fusion using the chosen gene subset, with a gradient of relatedness seen for unfused, fusing, and fused tissues (Fig. 2A). Furthermore, the unfused metopic suture grouped with the fused tissues, suggesting that metopic suture mesenchyme has an expression profile more similar to fused tissue. This result vindicated our exclusion of metopic suture samples from statistical analyses of differential expression between unfused and fused samples. All other unfused sutures showed a very high correlation in expression between themselves, whereas fused and fusing sutures were more disparate in expression profiles. This broader distribution of fusing and fused sutures may indicate that they were undergoing pathologic fusion of different aetiologies and/ or that they were at different stages of the fusion process. Additionally, there was evidence for suture-specific expression, with the unfused sagittal sutures being slightly less correlated to unfused coronal sutures than were unfused lambdoid sutures. This difference was later analysed by comparing expression solely between each unfused suture type; however by pooling unfused sutures for the initial analyses we were also able to identify those genes commonly involved in morphogenesis of all sutures. 
Table I: Phenotypes of patients, identified causative mutations, fusion state and site of obtained sutures.

\begin{tabular}{|c|c|c|c|c|c|c|c|c|}
\hline Analysis & Patient & Phenotype & Sex & Age (m) & Mutation & Fused Suture & Fusing Suture & Unfused Suture \\
\hline \multirow[t]{5}{*}{ Microarray } & $\# 42$ & Apert syndrome & M & 7 & FGFR2 Ser252Trp & $\begin{array}{l}\text { Coronala } \\
\text { Lambdoida }^{a}\end{array}$ & Metopic ${ }^{\mathrm{a}}$ & \\
\hline & \#36 & $\begin{array}{l}\text { Unicoronal } \\
\text { synostosis }\end{array}$ & $M$ & 3 & No FGFR or TWISTI & & Coronala $^{\mathrm{a}}$ & $\begin{array}{l}\text { Coronala } \\
\text { Sagittal }\end{array}$ \\
\hline & \#46 & Sagittal synostosis & $M$ & 5 & No FGFR or TWISTI & Sagittal & & $\begin{array}{l}\text { Coronal } \\
\text { Lambdoida } \\
\text { Metopica }^{\mathrm{a}}\end{array}$ \\
\hline & $\# 50$ & Sagittal synostosis & $M$ & 6 & No FGFR or TWISTI & Sagittal & & Coronal \\
\hline & $\# 58$ & Sagittal synostosis & $M$ & 7 & No FGFR or TWISTI & Sagittala & Sagittalb & $\begin{array}{l}\text { Sagittala } \\
\text { Coronal } \\
\text { Lambdoid }^{a}\end{array}$ \\
\hline \multirow[t]{19}{*}{ Validation } & $\# 47$ & Apert syndrome & $\mathrm{F}$ & 38 & FGFR2 Pro253Arg & Metopic & & \\
\hline & \#85 & Apert syndrome & $\mathrm{F}$ & 40 & FGFR2 Ser252Trp & Sagittal & Metopic & \\
\hline & \#90 & Apert syndrome & $\mathrm{F}$ & 4 & FGFR2 Pro253Arg & Coronal & Coronalc & $\begin{array}{l}\text { Sagittal } \\
\text { Metopic }\end{array}$ \\
\hline & $\# 61$ & Apert syndrome & $M$ & 20 & FGFR2 Ser252Trp & & Coronal & Coronal \\
\hline & \#92 & Muenke syndrome & $\mathrm{F}$ & 6 & FGFR3 Pro250Arg & & & Coronal \\
\hline & $\# 104$ & $\begin{array}{l}\text { Saethre-Chotzen } \\
\text { syndrome }\end{array}$ & $M$ & 14 & TWISTI c.256_276dup & $\begin{array}{l}\text { Sagittal } \\
\text { Metopic }\end{array}$ & & \\
\hline & $\# 49$ & Metopic synostosis & $M$ & 10 & No FGFR or TWISTI & Metopic & & \\
\hline & \#60 & Sagittal synostosis & $\mathrm{F}$ & 9 & No FGFR or TWISTI & Sagittal & Sagittal & \\
\hline & \#63 & Sagittal synostosis & $M$ & 10 & No FGFR or TWISTI & Sagittal & Sagittal & Lambdoid \\
\hline & \#72 & Lambdoid synostosis & $M$ & 26 & No FGFR or TWISTI & Lambdoid & & \\
\hline & \#91 & Sagittal synostosis & $\mathrm{F}$ & 5 & No FGFR or TWISTI & & & Metopic \\
\hline & \#94 & Metopic synostosis & $\mathrm{F}$ & 9 & No FGFR or TWISTI & Metopic & Metopic & Sagittal \\
\hline & \#95 & $\begin{array}{l}\text { Unicoronal } \\
\text { synostosis }\end{array}$ & M & 5 & No FGFR or TWISTI & Coronal & & \\
\hline & $\# 41$ & $\begin{array}{l}\text { Normal - Tessier } \\
\text { Cleft }\end{array}$ & $\mathrm{F}$ & 91 & Not tested & & & Metopic \\
\hline & \#69 & $\begin{array}{l}\text { Normal - } \\
\text { hydrocephalus }\end{array}$ & $\mathrm{F}$ & 4 & Not tested & & & Lambdoid \\
\hline & $\# 73$ & $\begin{array}{l}\text { Normal - cerebellar } \\
\text { tumour }\end{array}$ & $M$ & 9 & Not tested & & & Coronal \\
\hline & $\# 81$ & $\begin{array}{l}\text { Normal - } \\
\text { hydrocephalus }\end{array}$ & $\mathrm{F}$ & 2 & Not tested & & & Lambdoid \\
\hline & $\# 87$ & $\begin{array}{l}\text { Normal - cerebellar } \\
\text { tumour }\end{array}$ & $M$ & 57 & Not tested & & & Coronal \\
\hline & $\# 89$ & $\begin{array}{l}\text { Normal - } \\
\text { hydrocephalus }\end{array}$ & $M$ & I day & Not tested & & & Lambdoid \\
\hline \multirow[t]{5}{*}{ Histology } & \#3 & Apert syndrome & $M$ & 4 & FGFR2 Ser252Trp & Lambdoid & & \\
\hline & \#5 & Sagittal synostosis & $M$ & 3 & No FGFR or TWISTI & Sagittal & & \\
\hline & $\# 80$ & Metopic synostosis & $M$ & 6 & No FGFR or TWISTI & & & $\begin{array}{l}\text { Coronal } \\
\text { Sagittal }\end{array}$ \\
\hline & $\# 83$ & Sagittal synostosis & $M$ & 6 & No FGFR or TWISTI & & & $\begin{array}{l}\text { Lambdoid }(\times 2) \\
\text { Coronal }\end{array}$ \\
\hline & $\# 84$ & $\begin{array}{l}\text { Unicoronal } \\
\text { synostosis }\end{array}$ & $\mathrm{F}$ & 7 & No FGFR or TWISTI & Coronal & & Sagittal \\
\hline
\end{tabular}

aRNA sample also used for QRT-PCR validation experiments.

bSample used for validation experiments, but not microarray analysis.

CTwo samples of varying degrees of fusion were obtained. The sample which was at the earlier stage of fusion was used for validation qRT-PCR; the sample at a later stage of fusion was used for within patient comparison only.

Hierarchical clustering based on the selected subset of genes clearly showed that suture tissue samples formed two clusters, mirroring two states of fusion: fused/fusing and unfused (Fig. 2B). This suggests that fusing sutures are generally more similar to fused than unfused sutures and that it is appropriate to group them together for analyses. It was also noted that in both plots in Figure 2, sample
US36, despite RNA quality concerns, grouped most closely with the other unfused sagittal suture and thus it was appropriate to include this sample in further analyses. 


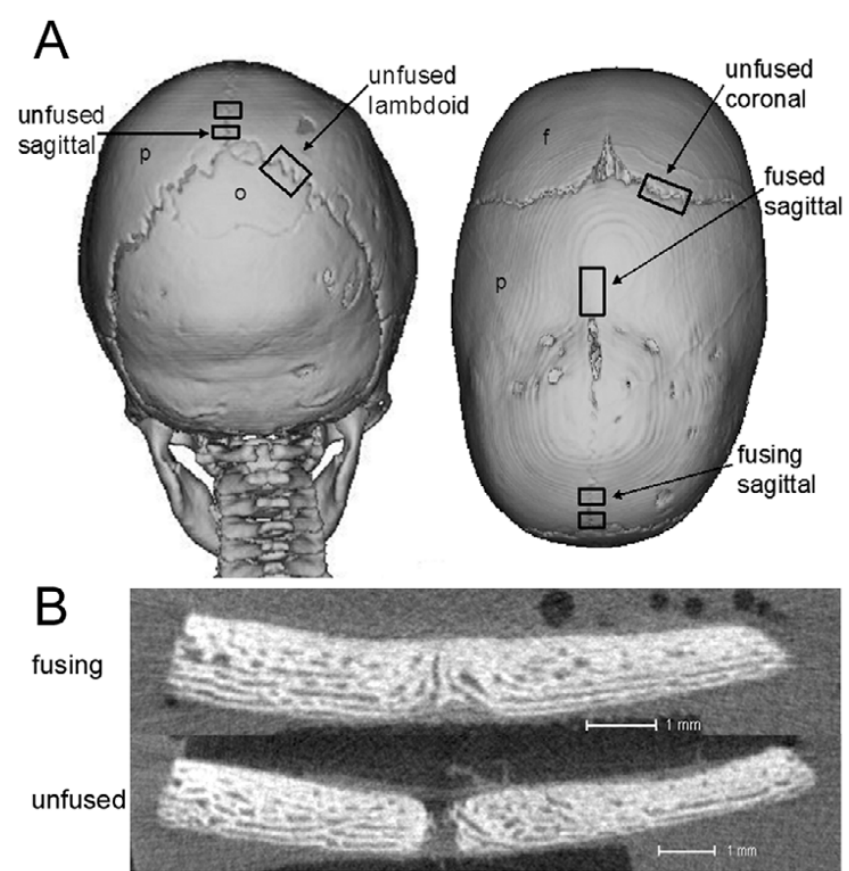

Figure I

Computer tomography (CT) scans showing site and fusion state of sutures obtained from craniosynostosis patients. A) Posterior and superior (left and right) view of patient \#58 indicating where unfused, fusing and fused sutures were obtained from. $p$, parietal bone; o, occipital bone; $f$, frontal bone. B) MicroCT image demonstrating a fusing and unfused suture. Scale I mm.

\section{Genes differentially expressed between fused and unfused sutures}

Based on a linear regression analysis of genes differentially expressed between the unfused group of sutures and the group of fusing/fused sutures, 28 genes were significantly (multiple testing corrected $P<0.05$ ) differentially expressed (Table 2). Irrespective of P-value, a greater than 2 -fold expression difference was found for 829 probe sets; 252 were "increased" and 577 were "decreased" in unfused compared to fusing/fused sutures (Additional file $5)$. Amongst those genes increased in unfused sutures were FGFR2, TGFB2, and epidermal growth factor receptor (EGFR) (Table 3). All have been previously linked with calvarial development and, in the case of FGFR2, with craniosynostosis [23-28]. Thirty two of these 829 probe sets $(3.9 \%)$, representing 24 genes, had a significant difference in expression (multiple testing corrected $P<0.05$ ), suggesting that these are important in the morphogenesis of all sutures. All, except one, were increased in unfused sutures. The identification of such a small number of significantly expressed genes across all suture types is likely due to the fact that different suture types, which may have slightly different gene expression profiles, were combined for the analysis. As we did not want to reject any potentially important genes, including those expressed to varying degrees in different sutures, we carried out further analyses using the genes in the 2-fold list, irrespective of their P-value. Importantly, however, we recognise that those genes with a $P<0.05$ are more likely to be key regulators of suture morphogenesis, rather than specific to one suture type.
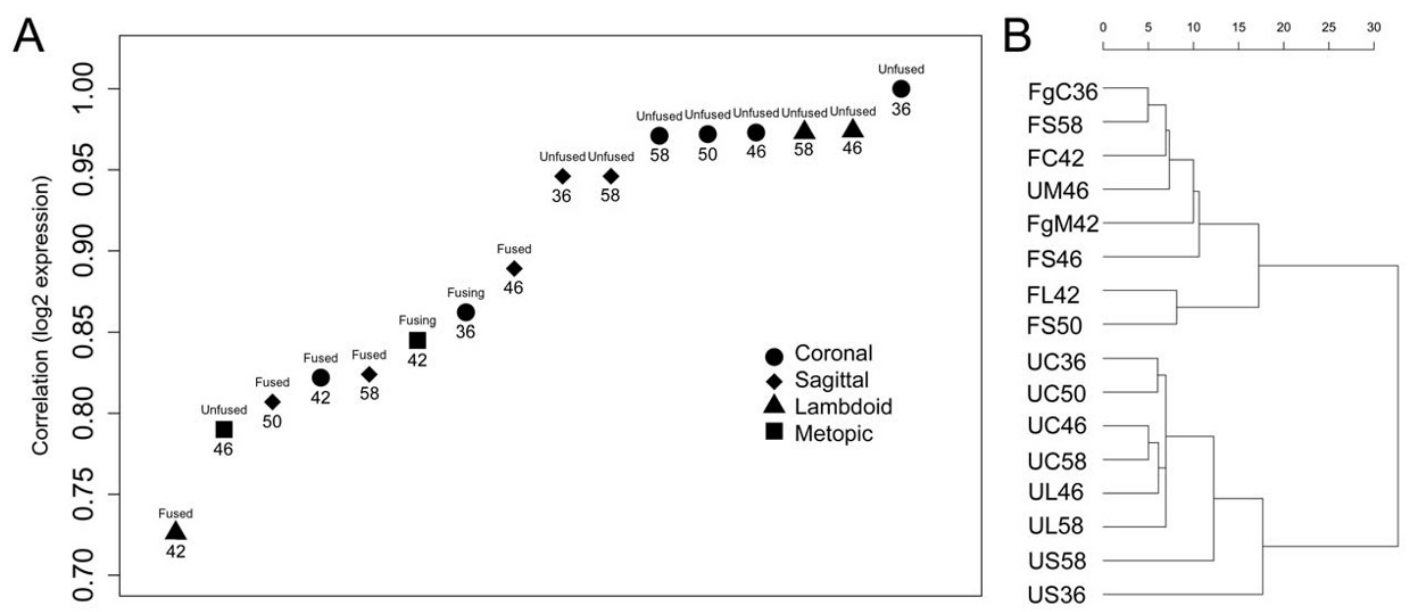

\section{Figure 2}

Microarray sample correlations based on a selected gene list (fused $\mathbf{v}$ unfused, $\boldsymbol{P}<\mathbf{0}$. I). Correlations are based on genes differentially expressed $(P<0.1)$ between unfused and fused sutures for combined samples from coronal, lambdoid and sagittal sutures. A) Correlation to the unfused coronal suture from patient \#36 shows a gradient of correlation between unfused, fusing and fused sutures. The unfused metopic suture groups with fused sutures. Patient number is recorded below data points and state of fusion above data points. B) Hierarchical clustering separates suture data into unfused and fusing/fused sutures. Unfused lambdoid and coronal sutures are more related to each other than they are to sagittal sutures. U, unfused; Fg, fusing; F, fused; C, coronal; S, sagittal; L, lambdoid; M, metopic; patient number follows sample identifier. 
Table 2: Significantly differentially expressed genes: unfused $\mathbf{v}$ fusing/fused sutures.

\begin{tabular}{|c|c|c|c|}
\hline Gene & GenBank & Name & Fold \\
\hline MFAP4 & NM 002404 & microfibrillar-associated protein 4 & 16.50 \\
\hline ILIIRA & NM 004512 & interleukin II receptor, alpha & 5.90 \\
\hline RBP4 & NM 006744 & plasma retinol binding protein 4 & 37.38 \\
\hline AMPH & NM 001635 & amphiphysin & 8.27 \\
\hline INHBA & NM 002192 & inhibin, beta $A$ (activin $A$, activin $A B$ alpha polypeptide) & 6.94 \\
\hline CIQTNF3 & $\underline{\mathrm{BC} 016021}$ & $\mathrm{Clq}$ and tumor necrosis factor related protein 3 & 20.25 \\
\hline PRELP & $\overline{\mathrm{BC} 032498}$ & proline arginine-rich end leucine-rich repeat protein & 10.65 \\
\hline$H D H D I A$ & NM 012080 & haloacid dehalogenase-like hydrolase domain containing IA & -1.78 \\
\hline$A G C I$ & NM 013227 & aggrecan I (chondroitin sulfate proteoglycan I) & 6.16 \\
\hline ANGPTL2 & NM 012098 & angiopoietin-like 2 & 6.67 \\
\hline Clorf24 & NM 052966 & chromosome I open reading frame 24 & 2.04 \\
\hline FMOD & NM 002023 & fibromodulin & 5.41 \\
\hline OLFMI & NM 006334 & olfactomedin I & 2.55 \\
\hline FBLNI & NM 006486 & fibulin I & 12.88 \\
\hline SSPN & NM 005086 & sarcospan & 4.40 \\
\hline CYFIP2 & $\underline{\mathrm{BC} 026892}$ & cytoplasmic FMRI interacting protein 2 & -2.68 \\
\hline MNI & NM 002430 & meningioma I & 3.72 \\
\hline PTN & NM 002825 & pleiotrophin (osteoblast-specific factor I) & 6.25 \\
\hline EGFR & NM 005228 & epidermal growth factor receptor & 2.71 \\
\hline TNN & NM 022093 & tenascin $\mathrm{N}$ & 6.67 \\
\hline$A D C Y 2$ & NM 020546 & adenylate cyclase 2 (brain) & 2.96 \\
\hline PDZRN3 & NM 015009 & PDZ domain containing RING finger 3 & 3.71 \\
\hline SPONI & $\underline{\mathrm{BC} 041974}$ & spondin I, extracellular matrix protein & 4.73 \\
\hline APP & NM 000484 & amyloid beta (A4) precursor protein & 1.83 \\
\hline AUTS2 & NM 015570 & autism susceptibility candidate 2 & 1.94 \\
\hline GPC3 & NM 004484 & glypican 3 & 7.13 \\
\hline HAPLNI & NM 001884 & hyaluronan and proteoglycan link protein I & 7.10 \\
\hline LHX6 & NM_014368 & LIM homeobox 6 & -1.80 \\
\hline
\end{tabular}

Twenty-eight genes were identified as being significantly (false discovery rate adjusted $P<0.05$ ) differentially expressed in unfused sutures compared to fused/fusing sutures. Genes are listed in order of significance with fold change relative to unfused sutures.

To further categorise the 2-fold differentially-expressed gene list, gene ontology (GO) over-representation was analysed. Biological processes enriched in the 2-fold gene list are shown in Table 4. Genes with higher expression in unfused sutures were found to significantly over-represent processes such as mesoderm formation, skeletal development, cell adhesion, cell surface receptor signalling, and extracellular matrix organisation, consistent with genes involved in regulating suture morphogenesis. Surprisingly, we also noted an extremely significant over-representation within those genes with higher expression in fusing/fused sutures of genes involved in the response to biotic stimuli $(\mathrm{P}=5.73 \times 10-41)$ and the immune response $(P=1.61 \times 10-34)$. As fold change is not the only useful characteristic, GO over-representation analysis was also conducted irrespective of fold change for all probe sets with a minimally selective $\mathrm{P}<0.25(\mathrm{n}=261)$ and similar categories were identified.

Gene Set Enrichment Analysis (GSEA) was then used to asses the significance of this set of differentially expressed genes at the molecular level. The ranked list of 2-fold differentially expressed genes was compared with a curated database consisting of molecular pathways and publicly available microarray experiments (Additional file 6). Such a comparison identifies which molecular pathways share a group of genes with our identified gene list, providing a potential insight into involved biological networks. Those gene sets which were significantly correlated (multiple testing corrected $P<0.05$ ) to genes increased in unfused sutures included genes with activating transcription factor 3 (ATF3) and lymphoid enhancer-binding factor 1 (LEF1) binding motifs within $2 \mathrm{~kb}$ of their transcription start sites, genes up-regulated by TGF $\beta$, genes up-regulated in haematopoietic stem cells, genes up-regulated in CD31 negative stromal stem cells which differentiate into bone cells, and genes down-regulated upon Cytomegalovirus $(\mathrm{CMV})$ infection. This final gene set makes a connection between those genes down-regulated during suture fusion (i.e. up-regulated in unfused sutures) and genes downregulated during infection. This integrated well with the gene sets which were significantly correlated with those genes increased during fusion; these included genes upregulated in liver in graft verses host disease (GVHD; particularly genes associated with attraction and activation of donor T-cells), genes up-regulated in pulpal tissue from 
Table 3: Selection of genes with fold change between unfused and fused sutures and between each unfused suture site.

\begin{tabular}{|c|c|c|c|c|c|c|c|}
\hline Gene Name & Affymetrix ID & Description & Fold U-F & P-value U-F & $\begin{array}{l}\text { Unfused } \\
\text { Lambdoid }\end{array}$ & $\begin{array}{l}\text { Unfused } \\
\text { Coronal }\end{array}$ & $\begin{array}{l}\text { Unfused } \\
\text { Sagittal }\end{array}$ \\
\hline \multicolumn{8}{|l|}{ Signalling } \\
\hline ANGPTNL2 & 213004_at & angiopoietin-like 2 & 6.67 & 0.024 & 1.00 & -1.45 & -2.87 \\
\hline EGFR & 201983_s_at & epidermal growth factor receptor & 2.71 & 0.038 & 1.00 & 1.02 & 1.20 \\
\hline EPHA3 & 20607I_s_at & EPH receptor $\mathrm{A} 3$ & 2.92 & 0.480 & 1.00 & -2.06 & -5.33 \\
\hline EPHA4 & 206 II4_at & EPH receptor A4 & 2.75 & 0.173 & 1.00 & -1.19 & -1.60 \\
\hline EPHB2 & 209589_s_at & EPH receptor B2 & 2.39 & 0.093 & 1.00 & 1.22 & -1.12 \\
\hline FGFR2 & 208228_s_at & fibroblast growth factor receptor 2 & 3.36 & 0.294 & 1.00 & -1.42 & -3.72 \\
\hline FZDI & 20445I_at & frizzled homolog I (Drosophila) & 2.13 & 0.326 & 1.00 & -1.08 & -2.41 \\
\hline ILIIRA & 204773_at & interleukin II receptor, alpha & 5.90 & 0.003 & 1.00 & 1.49 & 1.32 \\
\hline TGFB2 & 209909_s_at & transforming growth factor, beta 2 & 3.76 & 0.096 & 1.00 & -1.01 & -2.08 \\
\hline FGFRI & 222164_at & fibroblast growth factor receptor I & 1.23 & 0.480 & 1.00 & -1.29 & 1.12 \\
\hline FGFR3 & 204379_s_at & fibroblast growth factor receptor 3 & 1.42 & 0.480 & 1.00 & 1.23 & 1.33 \\
\hline WNT5A & 205990_s_at & $\begin{array}{l}\text { wingless-type MMTV integration site family, } \\
\text { member } 5 A\end{array}$ & 1.24 & 0.857 & 1.00 & -1.03 & -5.18 \\
\hline$I L I 7 R$ & 205707_at & interleukin 17 receptor & -2.67 & 0.480 & 1.00 & -1.25 & 3.35 \\
\hline OLFM4 & 212768_s_at & olfactomedin 4 & -6.69 & 0.480 & 1.00 & -2.15 & 6.77 \\
\hline WIFI & 204712 at & WNT inhibitory factor I & -3.19 & 0.480 & 1.00 & -1.27 & 5.37 \\
\hline \multicolumn{8}{|l|}{ Structural } \\
\hline COL2AI & 213492 at & collagen, type II, alpha I (primary osteoarthritis) & 7.21 & 0.390 & 1.00 & -20.66 & -3.84 \\
\hline COL3AI & 215077_at & $\begin{array}{l}\text { collagen, type III, alpha I (Ehlers-Danlos syndrome } \\
\text { type IV) }\end{array}$ & 6.32 & 0.072 & 1.00 & 1.24 & -3.84 \\
\hline COL8A2 & 221900_at & collagen, type VIII, alpha 2 & 11.49 & 0.092 & 1.00 & -1.23 & -12.73 \\
\hline COLIOAI & 217428_s_at & $\begin{array}{l}\text { collagen, type } X \text {, alpha I(Schmid metaphyseal } \\
\text { chondrodysplasia) }\end{array}$ & 14.65 & 0.407 & 1.00 & -41.66 & -17.28 \\
\hline FBLNI & 202995_s_at & fibulin I & 12.88 & 0.025 & 1.00 & -1.39 & -1.92 \\
\hline FMOD & 202709_at & fibromodulin & 5.41 & 0.024 & 1.00 & -1.09 & -1.70 \\
\hline NELL2 & 2034I3_at & NEL-like 2 (chicken) & 6.40 & 0.270 & 1.00 & -4.21 & -3.01 \\
\hline PRELP & 204223_at & $\begin{array}{l}\text { proline arginine-rich end leucine-rich repeat } \\
\text { protein }\end{array}$ & 10.65 & 0.009 & 1.00 & 1.20 & -1.31 \\
\hline THBS2 & 203083_at & thrombospondin 2 & 6.62 & 0.069 & 1.00 & -1.26 & -2.47 \\
\hline COLIA2 & 202404_s_at & collagen, type I, alpha 2 & 1.05 & 0.480 & 1.00 & -1.01 & -1.06 \\
\hline COROIA & 209083_at & coronin, actin binding protein, IA & -5.08 & 0.480 & 1.00 & -1.05 & 11.73 \\
\hline \multicolumn{8}{|l|}{ Transcription } \\
\hline BHLH3 & 221530_s_at & basic helix-loop-helix domain containing, class B, 3 & 5.95 & 0.093 & 1.00 & -2.23 & -4.76 \\
\hline CARTI & 206837_at & cartilage paired-class homeoprotein I & 2.06 & 0.533 & 1.00 & 16.21 & 2.38 \\
\hline$H L F$ & 204753_s_at & hepatic leukemia factor & 3.54 & 0.210 & 1.00 & -2.55 & -6.81 \\
\hline JUN & 201465_s_at & v-jun sarcoma virus 17 oncogene homolog (avian) & 4.41 & 0.161 & 1.00 & 3.14 & 2.50 \\
\hline PITX2 & 207558_s_at & paired-like homeodomain transcription factor 2 & 3.45 & 0.279 & 1.00 & 1.63 & -2.08 \\
\hline$S I X 2$ & 206510_at & sine oculis homeobox homolog 2 (Drosophila) & 2.72 & 0.136 & 1.00 & -1.09 & -1.70 \\
\hline FOS & 209189_at & $\begin{array}{l}\mathrm{v} \text {-fos FBJ murine osteosarcoma viral oncogene } \\
\text { homolog }\end{array}$ & 1.40 & 0.745 & 1.00 & 14.96 & 4.13 \\
\hline FOSB & 202768_at & $\begin{array}{l}\text { FBJ murine osteosarcoma viral oncogene homolog } \\
\text { B }\end{array}$ & 1.83 & 0.695 & 1.00 & 54.37 & 20.22 \\
\hline FOXDI & 206307_s_at & forkhead box DI & 1.49 & 0.499 & 1.00 & -4.71 & -5.17 \\
\hline JUNB & 201473_at & jun B proto-oncogene & 1.28 & 0.703 & 1.00 & 3.61 & 2.95 \\
\hline MEOX2 & 20620I_s_at & $\begin{array}{l}\text { mesenchyme homeo box } 2 \text { (growth arrest-specific } \\
\text { homeo box) }\end{array}$ & 1.66 & 0.495 & 1.00 & -3.99 & -7.74 \\
\hline MSX2 & 210319_x_at & msh homeo box homolog 2 (Drosophila) & 1.95 & 0.464 & 1.00 & -1.14 & -2.23 \\
\hline TWISTI & 213943_at & twist homolog I (Saethre-Chotzen syndrome) & 1.50 & 0.476 & 1.00 & -1.20 & -1.27 \\
\hline LHX6 & 219884_at & LIM homeobox 6 & -1.80 & 0.050 & 1.00 & -1.07 & -1.03 \\
\hline SHOX2 & 210135_s_at & short stature homeobox 2 & -3.44 & 0.480 & 1.00 & -1.00 & 4.50 \\
\hline PAX5 & 221969_at & paired box gene 5 (B-cell lineage specific activator) & -4.20 & 0.480 & 1.00 & -1.69 & 6.25 \\
\hline \multicolumn{8}{|l|}{ Catalytic Activity } \\
\hline RORI & 205805_s_at & receptor tyrosine kinase-like orphan receptor I & 2.26 & 0.095 & 1.00 & 1.21 & -1.14 \\
\hline$H D H D I A$ & 203974_at & $\begin{array}{l}\text { haloacid dehalogenase-like hydrolase domain } \\
\text { containing IA }\end{array}$ & -1.78 & 0.018 & 1.00 & 1.05 & 1.05 \\
\hline ALOX5 & 204446_s_at & arachidonate 5-lipoxygenase & -5.55 & 0.480 & 1.00 & -1.30 & 6.76 \\
\hline ANXA3 & 209369_at & annexin $\mathrm{A} 3$ & -7.17 & 0.480 & 1.00 & -1.30 & 6.76 \\
\hline
\end{tabular}


Table 3: Selection of genes with fold change between unfused and fused sutures and between each unfused suture site. (Continued)

\begin{tabular}{|c|c|c|c|c|c|c|c|}
\hline CIQTNF3 & 220988_s_at & $\mathrm{Clq}$ and tumor necrosis factor related protein 3 & 20.25 & 0.007 & 1.00 & -1.52 & -4.92 \\
\hline RBP4 & 219140_s_at & retinol binding protein 4 (plasma) KIAAI 922 & 37.38 & 0.003 & 1.00 & -1.35 & -2.53 \\
\hline APOCI & $204416 \times$ at & apolipoprotein C-I & -2.01 & 0.480 & 1.00 & 1.08 & 5.06 \\
\hline \multicolumn{8}{|l|}{ Binding } \\
\hline AGCI & 217161_x_at & aggrecan I (chondroitin sulfate proteoglycan I) & 6.16 & 0.024 & 1.00 & -1.25 & -1.56 \\
\hline CCNDI & 2087II_s_at & cyclin DI & 2.13 & 0.449 & 1.00 & 1.38 & 2.24 \\
\hline GPC3 & 209220_at & glypican 3 & 7.13 & 0.050 & 1.00 & 1.26 & -3.34 \\
\hline HAPLNI & 205523 at & hyaluronan and proteoglycan link protein I & 7.10 & 0.050 & 1.00 & -1.96 & -4.01 \\
\hline INHBA & 2105II_s_at & $\begin{array}{l}\text { inhibin, beta } A \text { (activin } A \text {, activin } A B \text { alpha } \\
\text { polypeptide) }\end{array}$ & 6.94 & 0.006 & 1.00 & -1.36 & -3.03 \\
\hline MFAP4 & 212713_at & microfibrillar-associated protein 4 & 16.50 & 0.001 & 1.00 & 1.32 & -1.86 \\
\hline OGN & 218730_s_at & osteoglycin (osteoinductive factor, mimecan) & 5.71 & 0.166 & 1.00 & $-1.4 \mid$ & -4.65 \\
\hline POSTN & 21498I_at & periostin (osteoblast specific factor 2) & 5.87 & 0.101 & 1.00 & -1.16 & -1.60 \\
\hline PTN & 209466_x_at & pleiotrophin (osteoblast specific factor I) & 6.25 & 0.031 & 1.00 & -1.14 & -1.78 \\
\hline SIOOAIO & 200872_at & $\begin{array}{l}\text { SI00 calcium binding protein A } 10 \text { (annexin II } \\
\text { ligand) }\end{array}$ & 2.01 & 0.096 & 1.00 & -1.04 & -1.60 \\
\hline CCND3 & 20I700_at & cyclin D3 & -2.60 & 0.480 & 1.00 & -1.00 & 3.62 \\
\hline FCNI & 205237_at & ficolin (collagen/fibrinogen domain containing) I & -5.45 & 0.480 & 1.00 & -1.46 & 12.39 \\
\hline FGR & 208438_s_at & $\begin{array}{l}\text { Gardner-Rasheed feline sarcoma viral ( } v \text {-fgr) } \\
\text { oncogene homolog }\end{array}$ & -3.03 & 0.480 & 1.00 & -1.13 & 5.75 \\
\hline SIOOA/2 & 205863_at & SI 00 calcium binding protein AI 2 (calgranulin C) & -8.86 & 0.480 & 1.00 & -2.63 & 15.19 \\
\hline \multicolumn{8}{|c|}{ Enzyme regulator } \\
\hline$M M P I 4$ & 202827_s_at & matrix metalloproteinase 14 (membrane-inserted) & 2.39 & 0.226 & 1.00 & -1.22 & -1.84 \\
\hline TIMP3 & 201149_s_at & tissue inhibitor of metalloproteinase 3 & 2.22 & 0.467 & 1.00 & $-1.7 \mid$ & -3.43 \\
\hline CASPI & 211366_x_at & caspase I, apoptosis-related cysteine protease & -2.73 & 0.165 & 1.00 & -1.30 & 1.01 \\
\hline$M M E$ & 203434_s_at & membrane metallo-endopeptidase (CDI0) & -3.23 & 0.476 & 1.00 & -2.35 & -1.29 \\
\hline MMP8 & 207329_at & $\begin{array}{l}\text { matrix metalloproteinase } 8 \text { (neutrophil } \\
\text { collagenase) }\end{array}$ & -5.81 & 0.480 & 1.00 & -2.36 & 1.69 \\
\hline RASGRP2 & 208206_s_at & $\begin{array}{l}\text { RAS guanyl releasing protein } 2 \text { (calcium and DAG- } \\
\text { regulated) }\end{array}$ & -2.60 & 0.480 & 1.00 & 1.02 & 3.02 \\
\hline \multicolumn{8}{|c|}{ Unknown Function } \\
\hline CYFIP2 & 220999_s_at & cytoplasmic FMRI interacting protein 2 & -2.68 & 0.031 & 1.00 & 1.14 & 1.09 \\
\hline
\end{tabular}

Gene expression fold change $(U-F)$ is presented for unfused sutures $(n=8)$ compared to fused/fusing sutures $(n=6)$, with corresponding $P$-values, and for combined unfused coronal $(n=4)$ and unfused sagittal $(n=2)$ sutures compared to unfused lambdoid sutures $(n=2)$.

carious teeth, and genes up-regulated during retinoic acid induced promyelocytic differentiation. These observations are consistent with our previous GSEA observations in a microarray comparison between fused sutures tissue and de-differentiated explant cells, where we again found an increase in expression of immune response genes in fused suture tissues [29]. It is possible that these immune response genes reflect the formation of bone marrow within the fused bone matrix. In support of this, microscopy revealed a large accumulation of lymphocytes and other white blood cells within the calvarial bones (Additional file 7). A second explanation may be that premature fusion is functionally associated with an immune response to infection, either directly or indirectly, as it is known that various immunoregulatory cytokines influence bone homeostasis and that osteoblasts may facilitate immune responses by producing immunomodulatory molecules (reviewed in $[30,31]$ ).

Results were then analysed on a gene-based level. One of the families of genes which were significantly over-represented in unfused sutures was Eph/ephrin signalling molecules. These form a pathway recently invoked in causing craniosynostosis [32,33]. Specifically, we found that three ephrin receptor genes had higher expression in unfused sutures (EPHA3, 2.9-fold; EPHA4, 2.8-fold; EPHB2, 2.4fold). Multiple genes from several other gene families were also increased in unfused sutures (Table 3). These include small leucine-rich proteoglycans (SLRPs), a group of secreted proteins that are known to be involved in cartilage and bone formation through facilitating collagen fibril binding to the EMC $[34,35]$ and regulating TGF $\beta$ activity by sequestering TGF $\beta$ in the ECM, thus preventing binding to cell surface receptors [36]. Such genes were, proline arginine-rich end leucine-rich repeat protein (PRELP, 10.7-fold), osteoglycin (OGN, 5.7-fold), fibromodulin (FMOD, 5.4-fold) and decorin (DCN, 2.0-fold).

A large over-representation of collagen genes was also observed. In particular, collagen type II, III, VI, VIII, X, and $X I$ were all up-regulated in unfused sutures. Interestingly, Collagen type II and X are generally associated with cartilage formation, and would not be expected to be expressed during intramembranous ossification. However, a number of other cartilage-specific genes were also increased in unfused sutures (AGC1,6.2-fold; HAPLN1, 
Table 4: Gene Ontology analysis: unfused compared to fused sutures

\begin{tabular}{|c|c|c|c|}
\hline $\begin{array}{l}\text { Biological process increased in } \\
\text { sutures: }\end{array}$ & Unfused & Fused & P-value \\
\hline Cell adhesion & 32 & & $1.95 \times 10^{-12}$ \\
\hline Cell matrix adhesion & 4 & & $6.53 \times 10^{-3}$ \\
\hline \multicolumn{4}{|l|}{ Cell communication } \\
\hline $\begin{array}{l}\text { Cell surface receptor linked signal } \\
\text { transduction }\end{array}$ & 25 & & $4.45 \times 10^{-3}$ \\
\hline Dopamine metabolism & 2 & & $6.63 \times 10^{-4}$ \\
\hline $\begin{array}{l}\text { Phosphoinsitide-mediated } \\
\text { signalling }\end{array}$ & & 8 & $4.58 \times 10^{-3}$ \\
\hline \multicolumn{4}{|l|}{ Cell differentiation } \\
\hline Heme biosynthesis & & 3 & $6.96 \times 10^{-3}$ \\
\hline Lymphocyte differentiation & & 6 & $1.27 \times 10^{-3}$ \\
\hline \multicolumn{4}{|l|}{ Cellular physiological process } \\
\hline Anion transport & 11 & & $4.92 \times 10^{-6}$ \\
\hline Cell cycle & & 42 & $4.72 \times 10^{-5}$ \\
\hline Cell motility & 11 & & $2.70 \times 10^{-4}$ \\
\hline $\begin{array}{l}\text { Extracellular matrix organisation } \\
\text { and biosynthesis }\end{array}$ & 4 & & $1.11 \times 10^{-3}$ \\
\hline Microtubule based process & & 10 & $7.35 \times 10^{-3}$ \\
\hline Regulation of phosphorylation & 3 & & $5.30 \times 10^{-3}$ \\
\hline Morphogenesis & 18 & & $5.34 \times 10^{-4}$ \\
\hline Cellular morphogenesis & 9 & & $5.60 \times 10^{-3}$ \\
\hline Mesoderm formation & 2 & & $4.46 \times 10^{-3}$ \\
\hline Organ morphogenesis & 8 & & $7.46 \times 10^{-3}$ \\
\hline Organ development & 23 & & $3.45 \times 10^{-7}$ \\
\hline Cartilage condensation & 2 & & $5.89 \times 10^{-3}$ \\
\hline Eye development & 3 & & $4.98 \times 10^{-4}$ \\
\hline Muscle development & 6 & & $2.52 \times 10^{-3}$ \\
\hline Skeletal development & 11 & & $1.18 \times 10^{-6}$ \\
\hline \multicolumn{4}{|l|}{ Regulation of development } \\
\hline $\begin{array}{l}\text { Negative regulation of } \\
\text { development }\end{array}$ & 3 & & $2.28 \times 10^{-3}$ \\
\hline \multicolumn{4}{|l|}{ Response to abiotic stimulus } \\
\hline Response to chemical stimulus & & 20 & $7.31 \times 10^{-3}$ \\
\hline $\begin{array}{l}\text { Response to reactive oxygen } \\
\text { species }\end{array}$ & & 3 & $5.21 \times 10^{-3}$ \\
\hline Response to biotic stimulus & & 116 & $5.73 \times 10^{-41}$ \\
\hline Defence response to bacteria & & 11 & $5.2 \times 10^{-9}$ \\
\hline Defence response to fungi & & 3 & $1.65 \times 10^{-3}$ \\
\hline Response to virus & & 7 & $9.11 \times 10^{-3}$ \\
\hline Immune response & & 100 & $1.61 \times 10^{-34}$ \\
\hline Humoral immune response & & 22 & $1.57 \times 10^{-8}$ \\
\hline Inflammatory response & & 23 & $3.08 \times 10^{-7}$ \\
\hline
\end{tabular}

Classification of gene ontologies (GO) significantly over-represented $(P<0.0 \mathrm{I})$ for genes at least 2 fold differentially expressed between unfused and fused sutures, listed under level $3 \mathrm{GO}$ category headings. Not all level three GO categories listed were significantly overrepresented and thus do not have a P-value

7.1-fold; CART1, 2.1-fold) suggesting that there may be a role for cartilage in calvarial suture morphogenesis. Additional secreted matrix proteins that were over-expressed in unfused suture tissue included pleiotrophin (PTN, also known as osteoblast specific factor 1 (OSF1)) and periostin (POSTN, osteoblast specific factor 2 (OSF2)). PTN has been identified in osteoblasts undergoing early stages of differentiation and is a potent regulator of osteoblast prolifera- tion, recruitment, and differentiation [37]. POSTN is also expressed by early osteoblasts and is a target of Twist 1 transcriptional regulation in mice [38]. A number of proteases and protease inhibitors were also differentially expressed between unfused and fused suture tissue including, MMP2 (2.0-fold), MMP14 (2.4-fold), MMP8 (5.8fold), MME (-3.23-fold), SERPINA1 (-2.7-fold), SERPINB1 (-3.6-fold) and TIMP3 (2.3-fold) (Additional file 5).

Numerous genes involved in Wnt signalling were also identified; glypican 3 (GPC3, 7.1-fold) and frizzled 1 (FZD1, 2.1-fold) were increased in unfused sutures, while WNT inhibitory factor 1 (WIF1, 3.2-fold) was increased in fused sutures. Previously, we have identified an up-regulation of WIF1 in human fused suture tissue when comparing in vivo expression to expression of de-differentiated explant cells [29]. These results are consistent with the recent observations that activation of canonical Wnt signalling is important in osteoblast expansion and differentiation [39], and that antagonist of Wnt signalling are essential to initiate terminal osteoblasts differentiation [40].

A number of the genes differentially expressed between fused, fusing, and unfused sutures which had a large significant $(P<0.05)$ fold change (Table 2$)$ had not been previously identified to be expressed in human calvaria. Of particular interest were retinol-binding protein 4 (RBP4, 37.4-fold, $P=0.003), C 1 q$ and tumour necrosis factor related protein 3 (C1QTNF3, 20.3-fold, $P=0.007$ ), microfibrillarassociated protein 4 (MFAP4, 16.5-fold, $P=0.001)$, PRELP (10.7-fold, $P=0.009)$, GPC3 (7.1-fold, $P=0.05)$, tenascin $N$ (TNN, 6.7-fold, $P=0.038$ ), pleiotrophin (PTN, 6.3-fold, $P=0.031)$ and interleukin 11 receptor alpha (IL11RA, 5.9fold, $P=0.003$ ). The significant expression of all these genes for the combined suture comparison suggests that they are likely to be key regulators of morphogenesis in all sutures.

\section{Unfused sagittal sutures have a lower expression of the 'unfused' class of genes}

To analyse the effect of suture type on gene expression we used two methods of analysis to compare global expression data between unfused coronal, sagittal, and lambdoid sutures. We then compared results from the two methods to identify the most robust set of differentially expressed genes. For the 3-way analysis we used a linear modelling approach to jointly perform three pair-wise comparisons: coronal vs sagittal, lambdoid vs sagittal, and lambdoid vs coronal and we then identified where these groups overlapped (Fig. 3). This pooled approach provides greater sensitivity and statistical power over multiple direct comparisons. Unfused sagittal sutures were found to have 340 probe sets differentially expressed when com- 
A

\section{Increased}

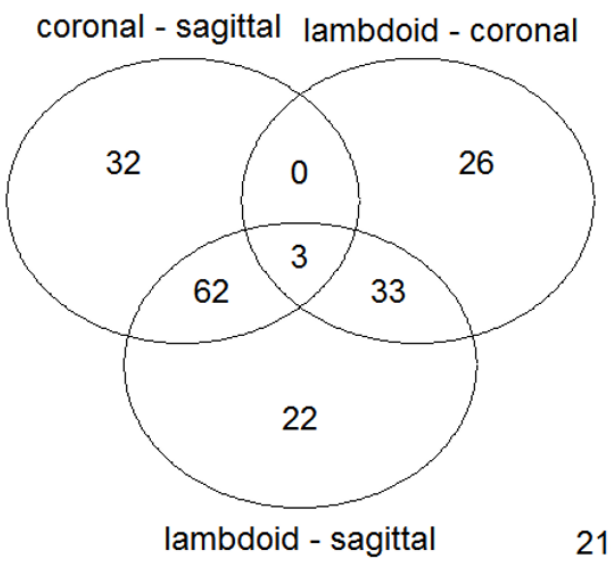

B

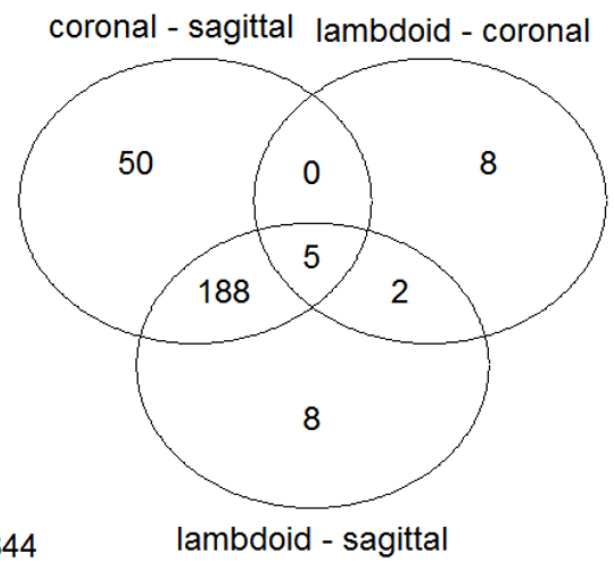

Figure 3

Venn diagram of 3-way unfused suture comparison results. Global expression differences were compared for 3 pair-wise comparisons (coronal vs sagittal, lambdoid vs coronal, lambdoid vs sagittal). The sagittal suture showed the greatest difference in gene expression to the other two sutures, followed by the lambdoid suture. A) Increased genes. 62 genes had similar increased expression in coronal and lambdoid sutures compared to sagittal sutures and 33 genes had increased expression in lambdoid sutures and similar expression in coronal and sagittal sutures. B) Decreased genes. 188 genes had similar decreased expression in unfused coronal and lambdoid sutures compared to unfused sagittal sutures and 2 genes had decreased expression in lambdoid sutures and similar expression in coronal and sagittal sutures.

pared to coronal sutures and 323 when compared to lambdoid sutures, while the coronal and lambdoid sutures only had 77 probes sets differentially expressed between each other. Furthermore, 250 of those probe sets differentially expressed in unfused sagittal were not differentially expressed between the coronal and lambdoid sutures. This supported the higher correlation of gene expression of differentially expressed genes between unfused coronal and lambdoid sutures seen in Figure 2. Of these 250 probe sets, 62 were increased in unfused coronal and lambdoid sutures and 188 were decreased, compared to the sagittal sutures (Fig. 3). The 3-way analysis also showed that 35 probe sets were uniquely expressed in unfused lambdoid sutures compared to coronal and sagittal sutures (33 increased and 2 decreased).

To control for patient-specific effects we performed a set of separate pair-wise comparisons using a matched pairs design. In this case we first restricted analysis to patients with a sample from each of the sutures of interest and then performed analysis on the within patient differences. A list of significant genes with $P<0.01$ was produced from each pair-wise comparison (Additional files 8, 9, 10).

The combination of the 3-way and pair-wise comparisons identified 100 probe sets significantly $(P<0.01)$ differentially expressed in unfused sagittal sutures compared to unfused coronal and lambdoid sutures. Amongst the top ten genes, seven had higher expression in unfused sagittal sutures and two had lower expression compared to coro- nal and lambdoid sutures (Fig. 4). Outside the top ten, genes with significantly decreased expression in unfused sagittal sutures were FGFR2, MSX2, GPC3, and WNT5A, while the Wnt inhibitor WIF1 had increased expression. The observed trend was that unfused sagittal sutures have a lower expression of those genes typically associated with an unfused suture state and a higher expression of genes associated with suture fusion (Table 3 ).

\section{Unfused coronal and sagittal sutures have differential expression of transcription factors compared to lambdoid sutures}

Analysis of the unfused-suture comparison data with respect to genes differentially expressed by unfused lambdoid sutures identified a large number of transcription factors. Those down-regulated with respect to coronal and sagittal sutures included FOS, FOSB, JUN, JUNB, and $C A R T 1$; all having a tendency for greater expression in the coronal suture (Table 3). Those genes with higher expression in unfused lambdoid sutures included transcription factors FOXD1, MEOX2, HLF and BHLH3.

\section{Microarray results validated by real-time quantitative $R T$ - PCR and Western blot}

Results from the microarray analysis were validated by qRT-PCR for 11 of the most highly expressed and significantly differentially expressed genes: eight genes increased in unfused suture tissue, RBP4, C1QTNF3, PRELP, GPC3, PTN, FMOD, COL3A1, and COL8A2; and 3 genes increased in fusing/fused suture tissue, WIF1, ANXA3, and 


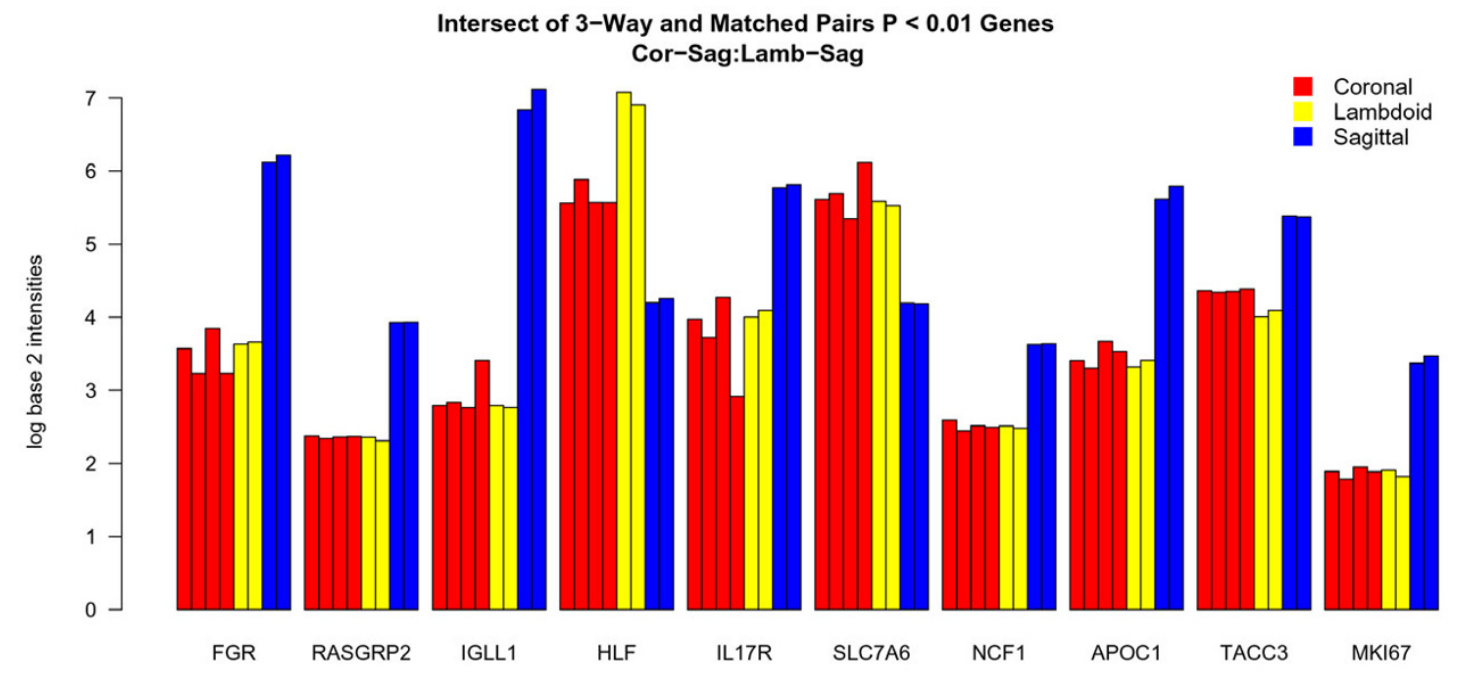

Figure 4

Top ten genes differentially expressed between unfused coronal, lambdoid and sagittal sutures. Genes commonly identified to be differentially expressed $(P<0.0 I)$ in unfused coronal and lambdoid sutures compared to unfused sagittal sutures, using two methods of microarray data analysis: 3-way and matched-pairs. Eight genes (FGR, RASGRP2, IGLLI, ILI 7R, NCFI, APOCI, TACC3, and MKI67) have higher expression in unfused sagittal sutures and two (HLF and SLC7A6) have lower expression compared to unfused coronal and lambdoid sutures. HLF shows a gradient of expression, highest in lambdoid, then coronal, then sagittal sutures, whereas the other genes show similar expression in coronal and lambdoid sutures. For each gene listed, sutures are in patient order: coronal (\#36, \#46, \#50, \#58), lambdoid (\#46, \#58), sagittal (\#36, \#58).

CYFIP2. The Affymetrix probe set for C1QTNF3 targeted two transcripts and therefore two transcript-specific primers sets were designed. Gene expression was analysed using 10 of the same RNA samples which underwent microarray analysis (Table 1). A linear correlation was calculated for each transcript for the comparison of expression values obtained by qRT-PCR and microarray analysis (Table 5). An average correlation of $90 \%$ was observed for all genes analysed, validating the microarray results. Three primer sets had a correlation coefficient smaller than $75 \%$; however, two of these primer sets did not amplify all isoforms detected by their corresponding Affymetrix probe set. The third primer set was designed to detect the long isoform of C1QTNF3. While this had a correlation of $74 \%$, the short isoform C1QTNF3 primers had 99\% correlation, suggesting that it is the short isoform of C1QTNF3 that is differentially expressed.

Table 5: Linear correlation between microarray and qRT-PCR data.

\begin{tabular}{llll}
\hline Gene & Probe Set & Slope & Correlation \\
\hline ANXA3 & 209369 at & 0.881 & 0.978 \\
WIFI & 204712 at & 0.850 & 0.982 \\
CYFIP2 & 220999 s_at & 0.785 & 0.748 \\
PTN & 211737 x_at & 1.063 & 0.905 \\
PRELP & 204223 at & 0.755 & 0.938 \\
FMOD & 202709 at & 0.867 & 0.851 \\
CIQTNF3 long isoform & 220988 s_at & 1.774 & 0.738 \\
CIQTNF3 short isoform & 220988 s_at & 0.806 & 0.990 \\
RBP4 & $219140 \_s \_a t$ & 1.100 & 0.968 \\
GCP3 & $209220 \_a t$ & 1.036 & 0.929 \\
COL8A2 & 221900 at & 1.261 & 0.854 \\
COL3AI & 215077 at & 0.767 & 0.709 \\
Average Correlation & & & 0.896
\end{tabular}

The average correlation for all probe sets is approximately $90 \%$, not including the correlation of the long isoform of CIQTNF3. The short isoform of CIQTNF3 had $99 \%$ correlation, indicating that the short and not the long isoform of CIQTNF3 is differentially expressed between unfused and fused sutures. 
To further examine the differential expression of genes between fused, fusing and unfused sutures identified by microarray analysis we used qRT-PCR to quantify expression of all genes noted above using the 10 validation samples and 25 additional samples from 13 new patients (Table 1). Although the initial microarray hierarchical clustering analyses (Fig. 2, Additional file 4) indicated there was limited difference in whole genome expression between non-syndromic and syndromic samples, this analysis only included samples from one syndromic patient. We therefore extended this comparison by analysing qRT-PCR data obtained from the larger cohort of patients which included 7 syndromic patients, and 11 non-syndromic patients in total. No significant difference $(P<0.05)$ in gene expression was seen between non-syndromic and syndromic samples, when separated into unfused, fusing, and fused states (Fig. 5A, Additional file 11). This result clearly demonstrates that samples of different aetiologies can be combined to investigate the general mechanisms of craniosynostosis.
As the unfused suture samples which underwent microarray and qRT-PCR analyses were obtained from patients with craniosynostosis, there is the possibility that their gene expression profiles do not truly represent an unfused suture from an individual without craniosynostosis. Consequently, the expression of the above mentioned genes were analysed in unfused coronal, lambdoid, and metopic sutures obtained from similar age-matched individuals who were undergoing transcranial surgery for reasons other than craniosynostosis (Table 1). No significant difference $(P<0.05)$ in gene expression was observed for these unfused non-craniosynostosis sutures, compared to unfused sutures from individuals with craniosynostosis (Fig. 5B). This provides proof of principle that the analysis of gene expression profiles from unfused sutures from craniosynostosis patients is useful in the study of suture morphogenesis.

qRT-PCR data was then compared between unfused, fusing, and fused samples from each suture site, combing
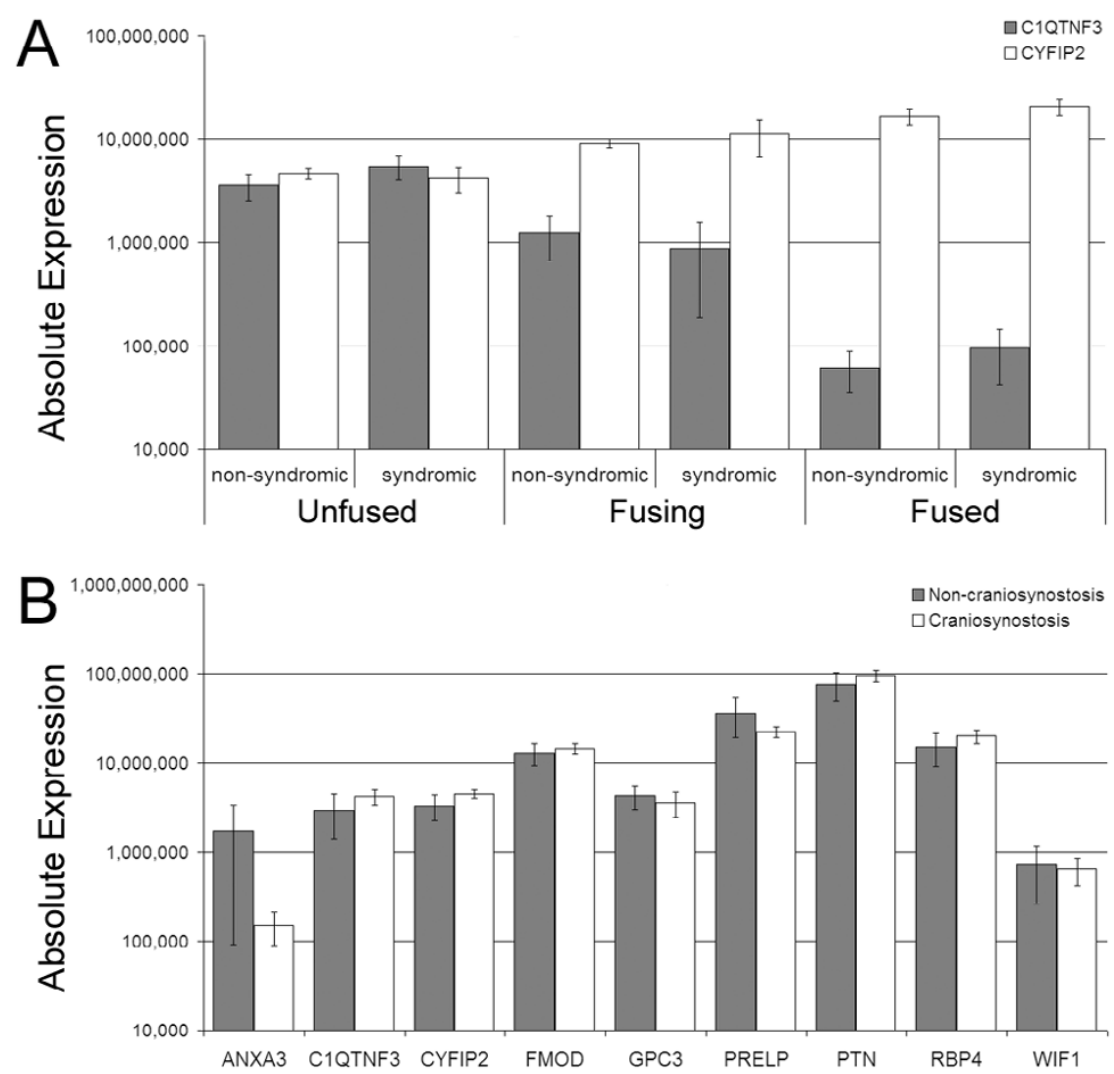

Figure 5

qRT-PCR expression data comparing syndromic, non-syndromic and non-craniosynostosis samples. A) No significant difference in expression exists between suture samples from syndromic and non-syndromic craniosynostosis patients. CIQTNF3 is decreased during fusion and CYFIP2 is increased during fusion, irrespective of aetiology. Samples from coronal, sagittal, lambdoid, and metopic sutures were combined for analysis. Samples numbers (left to right) are $n=8,4,5,4,7,7$. B) Unfused sutures from craniosynostosis patients $(n=12)$ and individuals without craniosynostosis $(n=6)$ show no significant difference $(P<0.05)$ in expression for all genes analysed. Absolute expression values represent molecules per ng cDNA. Mean expression \pm SEM is shown. 
non-syndromic and syndromic patients together. Differential expression profiles were observed for all 11 genes analysed, although the level of differential expression varied between suture sites (Fig. 6A, Additional file 12). The greatest difference in expression was observed for coronal sutures, followed closely by lambdoid sutures, while metopic sutures had, in general, the smallest changes in expression between unfused and fused sutures. This later observation is likely due to the finding that unfused metopic sutures generally had a lower level of expression of genes increased in unfused sutures (eg. C1QTNF3, $F M O D$ and $P T N$ ) and a higher expression of genes which were increased in fused sutures (eg. WIF1 and ANXA3).
Unfused sagittal sutures also showed higher expression than unfused coronal and lambdoid sutures for those genes increased in fused sutures (ANXA3 and WIF1) (Fig. 6A). These combined patient results confirmed the suturespecific analyses outlined earlier (Table 3, Fig. 2). The qRT-PCR validation experiment also demonstrated a variable gradient of expression between unfused, fusing, and fused samples for all genes analysed (Fig. 5A and Fig. 6A). However, this gradient of expression is best analysed using samples isolated from the same sutures from the same patient that are undergoing various stages of fusion. Figure 7 shows the qRT-PCR data from 5 samples isolated from one Apert syndrome patient (\#90). Two fusing coro-

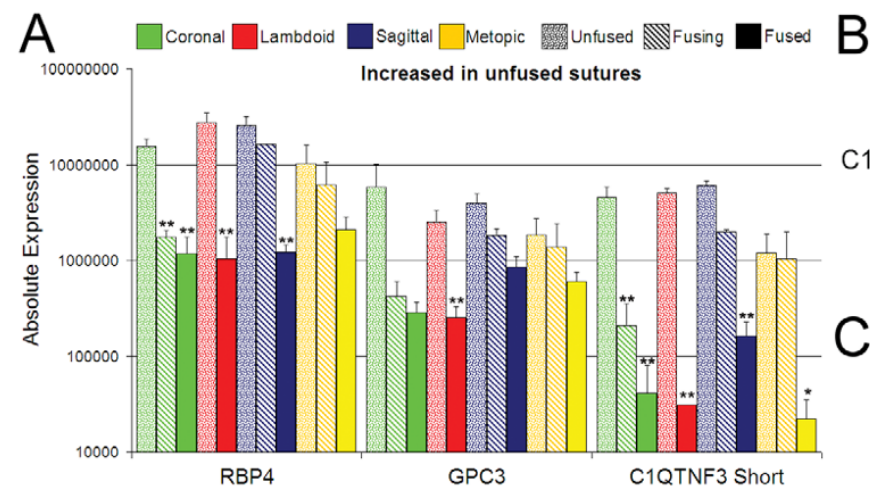

\section{B}
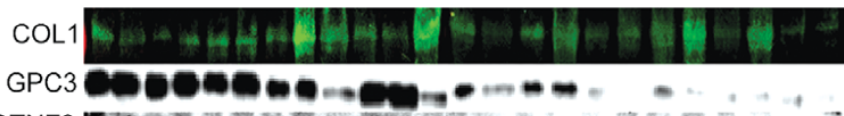

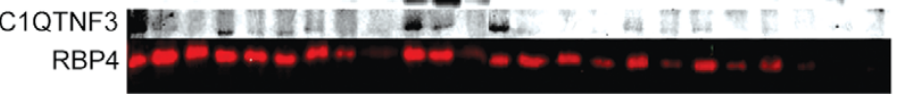

UU U U U UFgFg F U UF U U Fg Fg F F F F U U F F

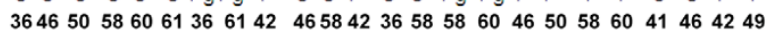
Coronal Lambdoid Sagittal Metopic
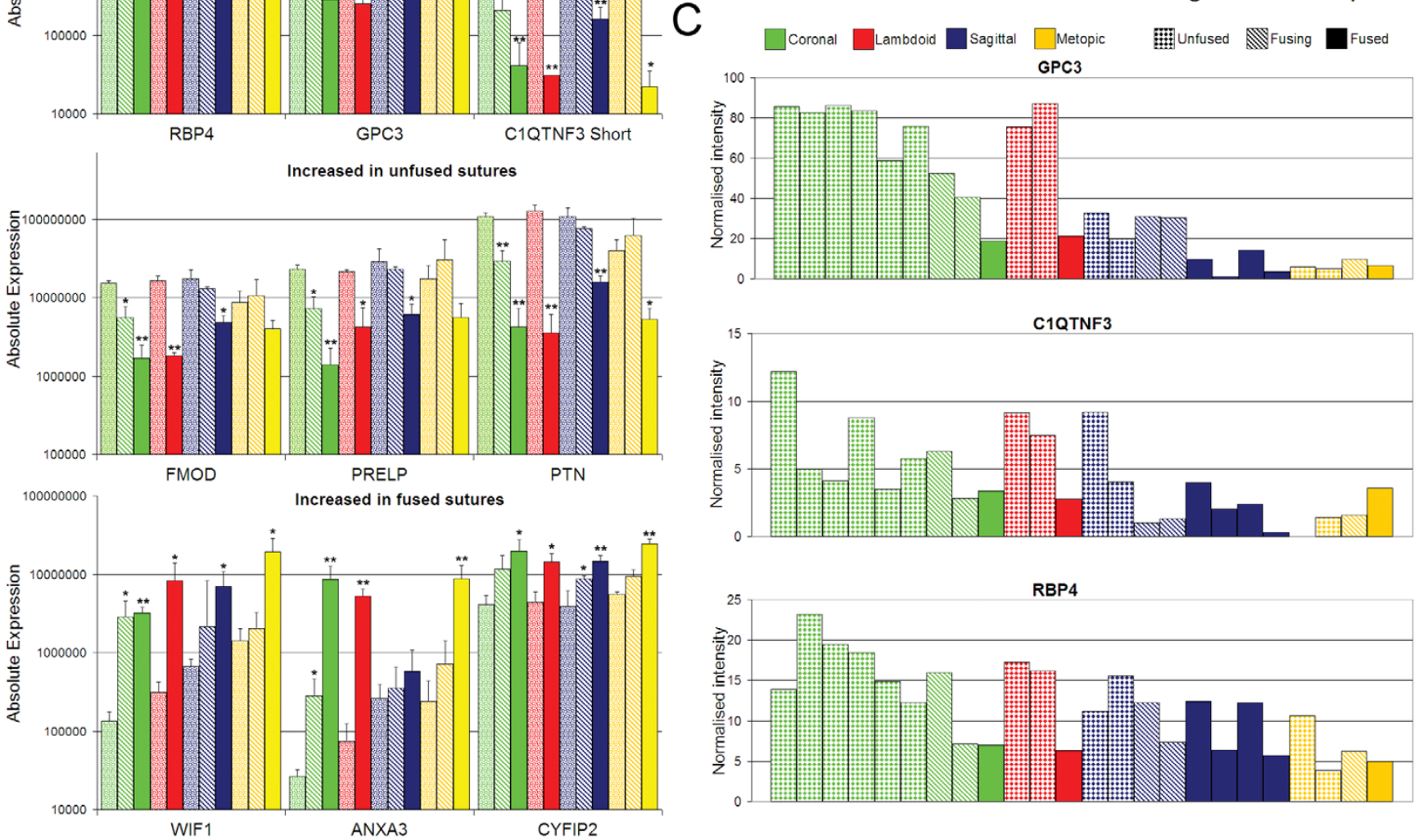

Figure 6

mRNA and protein validation of differential expression identified by microarray analysis. A) Real-time $q R T-P C R$ analysis of six genes with increased expression in unfused sutures (RBP4, GPC3, CIQTNF3 short isoform, FMOD, PRELP, and PTN) and three genes with increased expression in fused sutures (WIFI, ANXA3, and CYFIP2) for unfused, fusing and fused suture tissue isolated from sagittal, coronal, lambdoid and metopic sutures. Significant differential expression $(P<0.05, * ; P<0.01$, **) was analysed for fusing and fused sutures compared to unfused sutures. Mean expression + SEM is shown; $n=3$ for all comparisons, except fused sagittal $(n=5)$, fused metopic ( $n$ $=4)$, and fused lambdoid $(n=2)$. Absolute expression values represent molecules per ng cDNA. B) Western blot analysis of individual protein samples in the order seen in (C), for collagen type I (COLI), GPC3, CIQTNF3 and RBP4. C) Densitometry analysis of western blots normalised to COLI expression. 


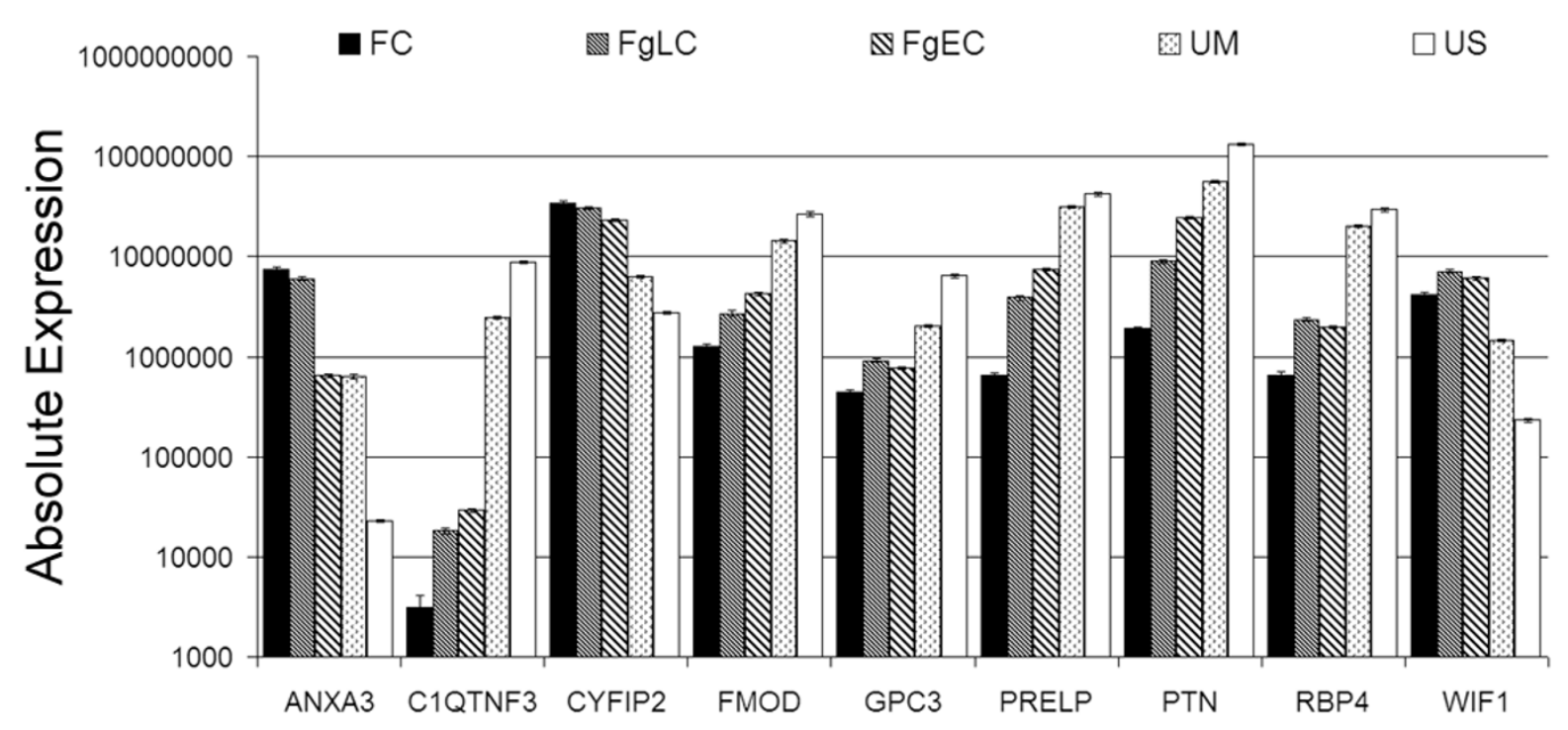

\section{Figure 7}

Within patient comparison of gene expression in fused, fusing, and unfused sutures. Gene expression was analysed in five suture samples from an Apert syndrome patient (\#90) by qRT-PCR. A gradient of expression is seen for all genes from unfused sagittal (US), to unfused metopic (UM), early fusing coronal (FgEC), late fusing coronal (FgLC), and fused coronal (FC) sutures. ANXA3 and CYFIP2 are increased highest in fused sutures, WIFI in fusing sutures and all other genes have highest expression in unfused sagittal sutures. Unfused Metopic sutures show higher expression of genes increased during fusion and a lower expression of genes increased in other unfused sutures. Absolute expression values represent molecules per ng cDNA. Error bars represent SEM for triplicate technical replicates.

nal samples were isolated from this patient, one during the early stages and one during the later stages of fusion, along with a fully fused coronal suture and unfused sagittal and metopic sutures. The data shows that ANXA3 and CYFIP2 are increased in fusing sutures, but are further increased in fully fused sutures, whereas WIF1 has the greatest expression in fusing sutures and is slightly decreased once the suture is fully fused, however this level remains above unfused sutures. This subtle difference cannot be seen in Figure 6A where fusing sutures of different stages from different patients are grouped together. Figure 7 also again highlights the difference in expression of unfused metopic sutures, being closer in expression to fusing sutures than other unfused sutures for a number of genes.

Differential protein expression was assessed by Western blot analysis for three genes with increased expression in unfused sutures, RBP4, C1QTNF3 and GPC3 (Fig. 6B and $6 \mathrm{C})$. Microarray results indicated that collagen type I alpha 2 was the most abundant transcript and was not differentially expressed between unfused and fused suture tissues (1.05 fold, Table 3 ). Protein expression was therefore normalised to COL1 for comparative quantification. All three proteins were differentially expressed in a similar pattern to that observed for the RNA expression data, with a decreasing gradient of expression observed for unfused, fusing, and then fused samples. Again, lower expression of each protein was observed in unfused metopic sutures. Higher protein expression was observed in two fused sagittal sutures (\#46 and \#58) compared to two other fused sagittal sutures (\#50 and \#60). This may be explained in part by tissue structure. During sample preparation it was noted that \#46 and \#58 sutures were very thin, flat bones more representative of developed calvaria, while \#50 and \#60 were more archetypal, having enlarged fused-suture ridges [5].

\section{Unfused Lambdoid sutures express cartilage-specific markers}

Increased expression of COL1OA1 and COL2A1 was identified in unfused lambdoid sutures and one (\#58) of the two unfused sagittal sutures compared to all other samples (Table 3). The unfused sagittal suture from patient \#58 was taken from the extreme posterior portion of the suture very close to the lambdoid suture (Fig. 1A). In all other gene expression analyses this sample grouped with the other unfused sagittal suture, verifying its correct classification as sagittal suture tissue. The expression of cartilage-specific collagens suggested, contrary to conventional thinking, that cartilage may play a role in human suture morphogenesis. Histological analysis of fused and unfused lambdoid, coronal, and sagittal sutures from additional patients to those used for microarray analyses (Table 1), identified cartilage only in unfused lambdoid sutures (Fig. 8). Cartilage was found at the tips of the oste- 



\section{Figure 8}

Cartilage localisation in unfused sutures. A-B) Serial H\&E and Alcian blue stain of right unfused lambdoid suture (\#83) showing cartilage (boxed regions expanded in panels $E$ and $F$, respectively) on either side of suture mesenchyme $(\mathrm{m})$ ). C) Alcian blue stain of left unfused lambdoid suture (\#83) showing cartilage fronts (box) surrounding suture mesenchyme. D) Cartilage front from panel C (box) showing proliferating (stacked cells) and hypertrophic (cells with enlarged lacunae) chondrocytes in a cartilage (c) matrix. E-F) Enlarged views of boxed regions in $A$ and $B$, respectively showing H\&E (E) and Alcian blue (F) stain of right unfused lambdoid suture (\#83) and highlighting cartilage interspersed with calcified bone (b, dark pink). Hematoxylin stains calcified matrix darker. G-H) Serial H\&E (G) and Alcian blue $(H)$ staining of an unfused coronal suture $(\# 83)$ showing no staining of cartilage in $(H)$. I-J) H\&E (I) and confocal immunofluorescence for Collagen type $X(\mathrm{~J})$ detected weak localisation (orange) in hypertrophic chondrocytes (ch), with intense (yellow) punctate localisation in osteoclasts (multi-nucleated cells, arrowhead) adjacent to the cartilage matrix of unfused lambdoid sutures (\#83). K) Collagen type $X$ protein was not detected in osteogenic fronts of unfused coronal sutures (\#83). Magnification: A-C, G-H: X3.2; D-F: XI2.5; Scale: I-K: $10 \mu \mathrm{m}$.

ogenic fronts which protruded into the suture mesenchyme. This cartilaginous region was composed of what histologically appeared to be a region of proliferating and hypertrophic chondrocytes, and was seen to protrude into the osteoblastic region where calcification was occurring to form calvarial bone (Fig. 8A-8F). The spatial expression of COLX protein, which is a specific marker of hypertrophic chondrocytes [41], was investigated by confocal immunofluorescence (Table 1). COLX was found to be highly abundant in osteoclasts, which were localised to the edges of the cartilage matrix adjacent to the bone matrix. COLX was also expressed, but more weakly, by chondrocytes in the cartilage matrix (Fig. 8I, J). COLX expression was not identified in any other suture type (Fig. 8K).

\section{Different spatial localisation of RBP4 and GPC3 in unfused sutures}

Tissue localisation of RBP4 and GPC3 was investigated using confocal microscopy in fused and unfused tissue from coronal, sagittal, and lambdoid sutures (Fig. 9). In all unfused sutures, RBP4 was located in the cytoplasm, the most intense staining being in osteocytes in the outermost region of bone overlying the suture region on the ectocranial but not the endocranial surface (Fig. 9A, B, E). RBP4 expression was also observed in osteoblasts at the osteogenic fronts (Fig. 9C, D), those invaginating the oste- 

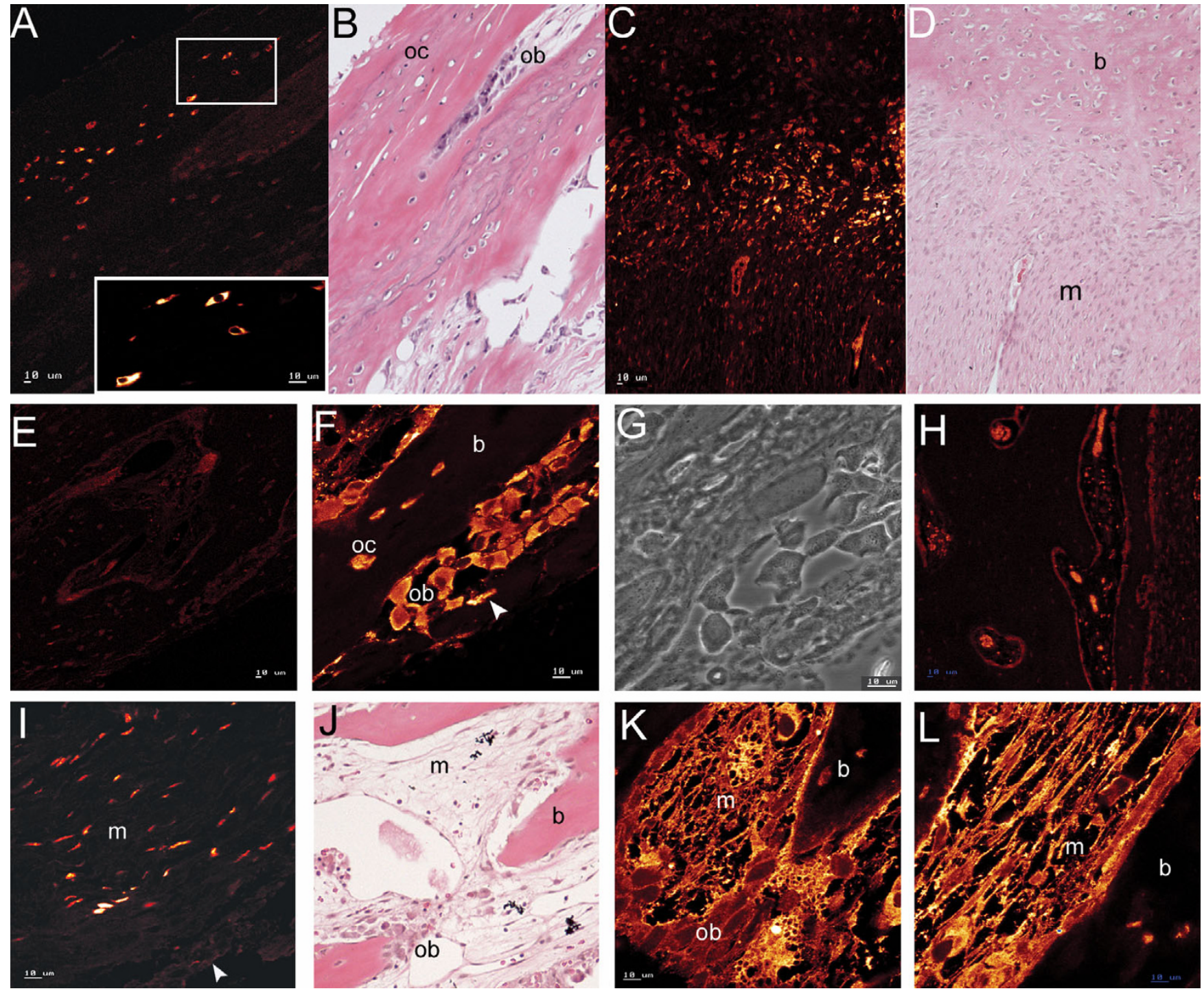

Figure 9

Localisation of RBP4 and GPC3 in suture tissue. A-B) Immunofluorescence and H\&E stain showing intense localisation (yellow) of RBP4 in the cytoplasm of osteocytes (oc) in ectocranial surface bone (unfused coronal suture, \#83). C-D) Serial immunofluorescence (C) and H\&E sections (D) showing RBP4 located in cells in the region between calcified tissue (b) and mesenchyme (m) (unfused left lambdoid suture, \#83). E) RBP4 was not detected on the endocranial surface of unfused sutures (coronal, \#83). F) RBP4 was localised to the cytoplasm of osteoblasts (ob) lining the developing bone, those being trapped in the osteoid (arrow head), and osteocytes (unfused coronal suture, \#83). G) Corresponding phase contrast image to the central region in (F). H) RBP4 was not detected in fused sutures. Red blood cells had weak autofluorescence (sagittal, \#5). I-L) GPC3 immunofluorescence (I) and H\&E (J) detected protein in mesenchymal cells close to the tissue surface (arrow head) in the mid-suture region (unfused sagittal suture, \#5). Membrane staining was observed for the cytoplasmic extensions of mesenchymal cells adjacent to calcified bone (K-L, unfused coronal suture, \#83). J) H\&E of section deep to (K) showing calcified bone protruding into intervening mesenchyme with osteoblasts lining the bone. Scale: $10 \mu \mathrm{m}$

oid, and by osteocytes at the bone margin (Fig. 9F, G), but not in osteocytes distal from the suture region. In the lambdoid sutures, RBP4 expression was also high in osteoblastic cells lining the cartilage fronts. No specific staining was observed in fused sutures (Fig. 9H).

Glypican 3 was most highly expressed in suture mesenchyme, particularly adjacent to the osteogenic fronts.
There was distinct cell surface staining of mesenchymal cells, clearly showing the delicate branching of their cytoplasmic extensions, forming an interlacing network throughout the suture space between bone fronts (Fig. 9J-L). Osteoblasts lining osteogenic fronts and those recently invaginated also had membranous staining although considerably weaker. There was also staining of mesenchymal cells close to the tissue surface in the mid- 
sutural region (Fig. 9I). The higher expression in mesenchymal cells correlates with the higher mRNA and protein expression in unfused compared to fusing and fused sutures (Fig. 6).

\section{Discussion}

Here, we have identified novel genes and attempted to gain a broader understanding of the various molecular pathways controlling suture morphogenesis in humans postnatally by analysing global gene expression differences between unfused sutures and prematurely fusing/ fused sutures from patients with craniosynostosis. This is the first study in which microarray analysis has been applied to investigate differential gene expression in fused, fusing, and unfused human sutures. We identified differentially expressed genes in pathways that have been a major focus of study in craniosynostosis, including FGF, TGF $\beta$ and EGF signalling pathways. In addition, we identified genes from the Eph/ephrin pathway that has recently been linked with craniosynostosis [32,33] and the Wnt pathway that is involved osteoblast differentiation [42] and transducing FGFR signals [43]. A number of novel genes which may have important roles in suture biology and which have not been previously linked with craniosynostosis have also been identified, specifically RBP4, GPC3, and C1QTNF3. All three are abundantly expressed in unfused sutures and are significantly downregulated in prematurely fused sutures.

\section{A role for retinol binding protein 4 in regulating retinoic acid induced osteoblast differentiation}

Retinol binding protein 4 (RBP4) expression was decreased 37 -fold in prematurely fused/fusing sutures compared to unfused sutures by microarray analysis. RBP4 is a secretable plasma protein that classically transports retinol from liver stores to tissues where it undergoes catalytic conversion into retinoic acid (RA) [44]. Extrahepatic RBP4 expression occurs in adipose, kidney, cartilage, and brain tissue and during embryonic development of the orofacial region [45-48]. It has been speculated that tissue-specific expression of RBP4 is linked to the binding of retinol from plasma in the immediate vicinity of, and for specific use by, its tissue of origin $[49,50]$. Our finding of RBP4 in osteocytes on the ectocranial surface of bone directly overlying the suture mesenchyme and by cells lining the osteogenic fronts, and its dramatic downregulation in suture fusion now implicates a role for it in suture morphogenesis and craniosynostosis. At teratogenic levels, the metabolite of retinol, RA, causes craniosynostosis and other developmental anomalies $[4,51,52]$. At physiologic levels, however, RA represses growth of preosteoblastic cells and enhances the expression of alkaline phosphatase, osteonectin, osteopontin, collagen type I and the osteoblast specific transcription factor RUNX2 [53,54]. RA also stimulates $B M P 2$ expression and cooperates to induce osteoblast dif- ferentiation [55]. Furthermore, primary rat calvarial osteoblasts treated with RA have increased osteopontin expression and switch from predominately expressing FGFR2 to FGFR1, representing a switch from active proliferation to osteoblast differentiation [56]. At physiologic levels, a function of this metabolite of retinol is therefore to suppress preosteoblastic proliferation and activate differentiation. This role of RA correlates with the localisation, reported here, of RBP4, the specific transporter of its precursor, in cells lining the ectocranial surface and the osteogenic fronts of unfused sutures and in those recently invaginated into the osteoid. RBP4 may therefore represent a primary regulator of osteogenesis in calvarial sutures by mediating the availability of retinol and its subsequent conversion to RA. In support of this, RBP4 knockout mice develop cranial malformations [57]. Taken together with our data on RBP4 expression during suture fusion and epidemiological evidence linking excess RA with craniosynostosis and other developmental anomalies $[4,51,52,58]$ we speculate that perturbations in the RBP4-retinol-RA axis may contribute to the occurrence of craniosynostosis.

\section{A role for glypican 3 in maintaining suture patency}

Glypican 3 (GPC3) is a cell surface heparan sulfate proteoglycan which binds to the extracellular surface of cells via a GPI (glycosyl-phosphatidyl-inisotol) anchor and is thought to facilitate interaction between various ligands and receptors. Loss-of-function mutations in GPC3 cause Simpson-Golabi Behmel syndrome (MIM 312870), an overgrowth syndrome with multiple skeletal abnormalities (large protruding jaw, widened nasal bridge, upturned nasal tip, and broad, short hands and fingers) that is associated with increased cell proliferation [59]. Our study shows that GPC3 expression is decreased 7-fold in prematurely fused/fusing sutures. GPC3 interacts with FGF2, WNT5a, and BMP-4 and -7 which are ligands of FGF receptors, WNT receptors (FZDs), and BMP receptors, respectively [60-62], all of which have been variously implicated in regulating osteoblast function. Molecular studies show that loss of GPC3 enhances the limb patterning defect of BMP4 heterozygous mice [62] and that GPC3 can bind FGF2 and suppress FGF2-induced cell proliferation [61]. GPC3 is also able to regulate the Wnt signalling pathway. GPC3 knockout mice exhibit an inhibition of the non-canonical Wnt/JNK signalling pathway, and activation of the canonical Wnt/ $\beta$-catenin signalling pathway [63]. Canonical Wnt/ $\beta$-Catenin signalling promotes osteoblast differentiation and bone accrual and inhibits osteoblast apoptosis (reviewed in [39]). We speculate that GPC3 controls cell growth within suture mesenchyme by regulating the bioavailability of FGFs, BMPs, and Wnts and might therefore acts as a gate-keeper of cell responsiveness in the suture. 


\section{A role for CIQTNF3 in suture morphogenesis}

C1QTNF3 (C1q tumor necrosis factor related protein 3), also known as CTRP3/cartducin, and CORS26, is a growth factor that hitherto had not been linked to suture morphogenesis. Our microarray study showed that C1QTNF3 expression is decreased 20-fold in prematurely fused/fusing sutures and qRT-PCR analysis determined that it is the short isoform of C1QTNF3 that is differentially expressed (Table 5, Fig. 6A). C1QTNF3 regulates proliferation of chondrocytes and their progenitor cells during both postnatal and embryonic development and has been shown to be up-regulated during BMP2 and insulin induction of chondrocyte differentiation [64]. C1QTNF3 has also been identified as promoting proliferation and migration of mouse endothelial MSS1 cells [65]. With the discovery of C1QTNF3 expression in unfused and fusing tissue of all sutures (Fig. 6), we predict a novel role for this growth factor in the regulation of osteoprogenitor proliferation and differentiation at the osteogenic fronts. Given our finding of cartilage-specific markers associated with posterior skull sutures we speculate that C1QTNF3 might also be involved in chondrogenesis in addition to osteogenesis in these sutures.

\section{The identification of cartilage in posterior sutures}

Of particular interest was the identification in our microarray experiment of increased expression of genes coding for cartilage-specific collagens types $I I$ and $X$ in the two unfused lambdoid and the unfused sagittal sutures from the posterior of the skull. The involvement of cartilage in unfused lambdoid sutures was confirmed histologically through the observation within the region of the osteogenic fronts of a cartilaginous matrix which protruded into the suture mesenchyme and adjacent calcified bone matrix (Fig. 8). In addition, confocal microscopy localised collagen type $\mathrm{X}$ to chondrocytes in the cartilage matrix and in osteoclasts adjacent to cartilage (Fig. 8I, J). Identification of what is termed 'secondary cartilage' has been previously noted in several human calvarial sutures, with a high incidence in normal lambdoid sutures [66,67]. It has been proposed that this secondary cartilage may develop in response to the higher mechanical forces applied to the posterior region of the skull during growth as it provides a matrix more tolerant to compression [5]. Cartilage has also been observed in rodent sutures where a cartilaginous plate underlies the lambdoid suture, possibly forming a supportive structure on which intramembranous ossification occurs [24]. Recently, cartilage and chondrocytic markers have also been identified in sagittal sutures of transgenic mice generated with the Apert syndrome FGFR2 S252W mutation [68]. The cartilage was located at the junction of the parietal and interparietal bones which corresponds to the region from which the sutures we identified as expressing cartilage-specific genes were isolated. Importantly, we demonstrated that cartilage is present within the osteogenic fronts, rather than underlying the sutures suggesting a functional rather than supportive role. Recently, Sox9, a regulator of chondrogenesis, has been shown to be upregulated during the initiation of posterior frontal suture closure in mice, along with the expression of collagen types II and $X$, followed by collagen type I and osteocalcin expression [69]. A role for endochondral ossification was therefore proposed to control fusion of this suture. Additionally, collagen types II and aggrecan have been detected in preosteogenic-condensing mesenchyme and the osteogenic fronts of developing embryonic chick heads [70]. It was proposed that, in chickens, normal intramembranous ossification includes a transient chondrogenic phase. The identification, in our study, of cartilage in lambdoid suture mesenchyme also suggests that chondrogenesis plays a role in human suture morphogenesis, particularly in the posterior skull.

\section{Distinctive tissue-type specific gene expression differences} The analysis of gene expression in the different suturetypes indicated that gene expression profiles of unfused metopic sutures were more highly correlated with the expression exhibited by fused sutures from other suture sites; specifically they showed a significantly lower expression of those genes increased in other unfused sutures (Fig. 6A, 7). This unique expression profile may help explain the earlier occurrence of metopic suture fusion during development. Unfused coronal and unfused lambdoid sutures also showed very similar expression profiles. Both these sutures are generally formed by overlapping calvarial bone fronts, in comparison to the blunt-end sutures which form the sagittal and metopic sutures [5]. These sutures are also similar in that they are a meeting of bones of two different developmental origins (mesoderm and neural crest cells) while the sagittal and metopic sutures are the meeting point of bones of one origin, either mesoderm or neural crest, respectively.

Transcription factors are key controllers of the signalling cascades activated during development. Of those transcription factors differentially expressed between fused and unfused suture tissue a majority also showed significant expression differences between suture types. Unfused sagittal sutures had a higher expression of homeobox genes SHOX2 and PAX5 which potentially drive osteoblast differentiation and generally had increased expression in fused sutures. The unfused sagittal sutures also showed a lower expression of MSX2, SIX2, PITX2, BHLH3, and $H L F$ that were generally increased in other unfused sutures compared to fused sutures. Given the higher frequency of non-syndromic craniosynostosis in the sagittal suture we speculate that a lower expression of transcription factors associated with unfused sutures, and a higher expression of those associated with fused sutures, might leave this suture more vulnerable to premature closure. 
Both unfused sagittal and unfused coronal sutures had significantly higher expression of members of the FOS (FOS and FOSB) and JUN (JUN and JUNB) oncogene families compared to unfused lambdoid sutures, particularly for coronal sutures (eg. FOSB was 54.4-fold increased in the coronal sutures, compared to 20.2-fold in the sagittal sutures). Through homo- and hetero-dimerisation, these proteins form the AP-1 transcription complex. Increased Jun and Fos expression occurs in prematurely fused mouse sutures induced by the application of FGF2soaked beads [71]. It was suggested that FGF signalling increases expression of the AP-1 complex which then induces expression of osteopontin and osteoblast differentiation, resulting in premature suture closure. It is also known that the coronal and sagittal sutures are those most frequently affected in FGFR syndromic craniosynostoses. We therefore suggest that the higher expression of AP-1 transcription factor components in coronal and sagittal sutures makes them more responsive to the increased or inappropriate FGF signalling caused by gain-of-function FGFR mutations. However, it was also observed that unfused sagittal sutures had decreased expression of FGFR2 compared to the coronal suture. This may explain why mutations in these genes most commonly affect the coronal suture rather than the sagittal suture.

Another important finding from our microarray analysis was that there was limited difference in whole genome expression between non-syndromic and syndromic patient samples. This was verified by qRT-PCR using 35 samples from 7 syndromic and 11 non-syndromic patients, analysing 11 genes differentially expressed between unfused and fused sutures. We note, however, that these genes were identified as being significantly differentially expressed during premature fusion by using tissue groups which contained samples from patients with different aetiologies. Thus, we specifically identified genes which were not specific to one aetiology. If these two groups of samples were analysed independently, it is likely that there may be a small proportion of genes which are differentially expressed between samples from patients with different aetiologies and these genes will be directly related to the mutation of initiation. However, in this study we were not so interested in these aetiology specific indicators, but rather the general mechanisms underlying craniosynostosis. Significantly, the results from our microarray hierarchical analysis study indicate that the genes involved in the pathogenesis of different types of craniosynostosis are more similar than may previously have been thought.

\section{Conclusion}

Through the analysis of human suture material we have identified a large number of novel differentially expressed genes, three of which, RBP4, GPC3 and C1QTNF3, we believe may have significant regulatory roles in the control of both suture patency and growth. Furthermore, we have identified significant gene expression differences between human sutures from different cranial sites and identified the involvement of cartilage in posterior calvarial sutures, particularly the lambdoid suture. These data open up new avenues of investigation in respect to the molecular mechanisms underlying the different responses of calvarial sutures to mutations causing craniosynostosis. This information is vital for the development of therapeutic agents to control skull growth in children with sutural defects, as well as providing clinicians with a better understanding of the developmental mechanisms operating in different sutures.

\section{Methods \\ Tissue Samples}

Calvarial suture samples were obtained from patients undergoing transcranial surgery for syndromic or nonsyndromic craniosynostosis. Patients were genotyped for all known FGFR1-3 and TWIST1 mutations (Table 1) [72]. Samples used for microarray analysis $(n=16)$ were taken from males $(n=5)$ aged 3-7 months. Additional samples used for validation experiments $(\mathrm{n}=25)$ and histology $(n=9)$ were taken from female $(n=8)$ and male $(n$ $=10$ ) patients aged 3-40 months. Additionally, six unfused suture samples were obtained from patients aged 1 day to 91 months undergoing transcranial surgery for reasons other than craniosynostosis (Table 1). Consent was provided by all guardians in line with the guidelines of the Research Ethics Committee of the Children, Youth and Women's Health Service, Adelaide, South Australia. Suture tissue was taken from prematurely fused/fusing and/or patent sutures from one or more of the sagittal, coronal, lambdoid, and metopic sutures. The site and fusion state of samples used for each analysis type are indicated in Table 1. Specimens used for microarray analysis and validation experiments were stored in RNAlater (Ambion, Austin, TX, USA) at $-20^{\circ} \mathrm{C}$. Specimens used for histology and immunofluorescence were fixed in formalin, decalcified with $10 \%$ EDTA, pH 7.4, by standard procedures and stored in $100 \%$ ethanol.

\section{DCT and MicroCT scans}

Stage of fusion was confirmed by assessing 3D computer tomography (CT) images taken prior to surgery. Selected suture samples underwent MicroCT analysis to determine the degree of fusion, as previously described [73]. Briefly, tissues samples were placed in RNAlater, enclosed tightly in an acrylic tube, and analysed with a SkyScan 1072 MicroCT scanner (SkyScan, Antwerp, Belgium). 2D images were used to generate $3 \mathrm{D}$ reconstructions using $3 \mathrm{D}$ creator software (SkySkan). 


\section{Total RNA isolation}

Tissues used for microarray analysis and validation experiments had the suture proper (suture mesenchyme +3 $\mathrm{mm}$ bone on either side for unfused sutures, or fused bony ridge $+3 \mathrm{~mm}$ bone on either side for fused sutures) dissected from all specimens and the overlying pericranium was removed. Tissue samples were cut into 30-40 $\mu \mathrm{g}$ pieces for RNA extraction, snap frozen, crushed between cryogenically cooled steel blocks, and homogenised in 2 ml TRIreagent (Molecular Research Center, Cincinnati, OH, USA) using a Mini-Bead-Beater-8 (BioSpec Products, Bartlesville, OK, USA). RNA was isolated from supernatant following recommendations by Naderi et al. [74]. Briefly, separated aqueous phase was twice extracted with chloroform and precipitated with 1 volume isopropanol, 0.1 volume $7.5 \mathrm{M}$ ammonium acetate, and $5 \mu \mathrm{g} / \mathrm{ml}$ linear polyacrylamide (Ambion) at $-20^{\circ} \mathrm{C}$ overnight. Pelleted RNA was washed twice with $70 \%$ ethanol and resuspended in RNA Storage Solution (Ambion). RNA extracts from the same sample were combined. $10 \mu \mathrm{g}$ of each combined RNA sample was purified and concentrated to greater than $300 \mathrm{ng} / \mu \mathrm{l}$ with phenol:chloroform:isoamyl alcohol (25:24:1) extraction. Total RNA quality was determined by analysing the integrity of the $28 \mathrm{~S}$ and $18 \mathrm{~S}$ ribosomal bands on a non-denaturing 1.5\% agarose Trisborate buffered gel and determining RNA purity by A260:280 ratios using UV spectroscopy.

\section{Microarray cDNA synthesis, hybridisation, and scanning}

RNA from 16 tissue samples (Table 1) was analysed using the Affymetrix expression microarray Human U133A 2.0 GeneChip platform. Concentrated total RNA was prepared for hybridisation to the GeneChips following a onecycle target labelling protocol (Affymetrix GeneChip Expression Analysis Technical Manual). RNA was reverse transcribed into double stranded cDNA using SuperScript II (Invitrogen, Gaithersburg, MD, USA) with T7-oligomers. Poly-A RNA spike-in controls were added along with $2 \mu \mathrm{g}$ of total RNA to all cDNA reactions. Biotin labelled cRNA was prepared from the cDNA using the GeneChip IVT labelling system (Affymetrix, Santa Clara, CA, USA), with incubation at $37^{\circ} \mathrm{C}$ for 16 hours. $10 \mu \mathrm{g}$ of fragmented cRNA was hybridised to each Affymetrix U133A 2.0 GeneChip. Array hybridisation, staining, and washing was carried out following manufacture's protocols using the Fluidics Station 400 (Affymetrix). Stained arrays were scanned on a GeneChip Scanner 3000 (Affymetrix) controlled by GCOS software (Affymetrix).

\section{Microarray data analysis}

CEL files containing probe intensity data were analysed in R using Bioconductor packages [75,76]. Quality control analyses were carried out on probe level model (PLM) normalised samples. Normalised un-scaled standard error (NUSE) box plots, Mbox plots, and RNA degradation plots were analysed [77]. For statistical analyses probe intensity data were normalised using the GeneChip Robust Multichip Average (GCRMA) algorithm, which has been shown to provide a good balance between accuracy and precision [78]. Diana-divisive hierarchal clustering was used to cluster the microarray samples based on whole genome expression values. To identify differential gene expression the Limma package was used to fit linear models to the data, incorporating an empirical Bayes modification of the standard errors [79]. False discovery rate adjustment of P-values was performed to account for multiple testing [80]. Correlation plots and hierarchal trees were generated using cluster packages available in $\mathrm{R}$. Gene ontology over-representation was analysed using GOTree Machine, normalising to the U133A 2.0 gene set, with significance set at $P<0.01[81,82]$. Gene set enrichment analysis was carried out using GSEA v 2.01, comparing the ranked list of 2-fold differentially expressed probe sets to gene sets c1-c4 (v2.symbols.gmt) [83,84]. Gene set exclusion was set at $\min =4, \max =500$, with 1000 weighted permutations executed. A 3-way contrast matrix was created for the unfused suture comparisons: coronalsagittal, lambdoid-sagittal, and lambdoid-coronal. Using the Limma package a Venn diagram was produced for those genes identified to be differentially expressed using a nested F-test approach which gives particular attention to genes which are differentially expressed $(P<0.01)$ under 2 or more conditions. To control for patient-specific effects due to the small sample size of this comparison, we performed a set of separate pair wise comparisons using a matched pairs design. In this case we first restricted analysis to patients with a sample from each of the sutures of interest, and then performed analysis on the within patient differences. A matched-pairs matrix was constructed for an unfused coronal-lambdoid comparison using samples from patients \#36 and \#46 and a coronal and sagittal comparison using samples from patients \#36 and \#58. A t-test was performed between unfused lambdoid and sagittal samples from patients \#36, \#46 and \#58. A linear model incorporating an empirical Bayes modification was applied to each matched pairs comparison. To identify genes differentially expressed in unfused sagittal sutures, the intersection of the 3-way and matched pairs coronal-sagittal comparison and lambdoid-sagittal comparisons was found.

\section{Realtime quantitative RT-PCR (qRT-PCR)}

Total RNA was reverse transcribed into cDNA using SuperScript III (Invitrogen). Two micrograms of RNA was added to $40 \mu \mathrm{l}$ total volume reactions which were carried out following the manufacturer's protocol. In addition to the patient RNA samples, a calibrator RNA sample which was used to standardise absolute qRT-PCR results, was transcribed into cDNA, column purified (QIAquick PCR purification kit, Qiagen, Clifton Hill, VIC, Australia) and 
quantified by UV spectroscopy. cDNA from all samples was diluted $1 / 3$ and $1 / 120$ with TE (pH 8 ) and supplemented with herring sperm DNA to $1 \mathrm{ng} / \mu \mathrm{l}$. The $1 / 120$ dilutions were used for the amplification of the $18 \mathrm{~S}$ rRNA gene and the $1 / 3$ dilutions were used for the analysis of all other genes. Absolute quantification was carried out using standard curves generated by serial dilution of target amplicon-containing plasmids (pGEM-T easy, Promega, Annandale, NSW, Australia), to cover up to 5 logs of amplicon copy number per microlitre. All primers were designed to target the same sequence as the microarray probes, to overlap exon-exon junctions, and to have a melting temperature of $60^{\circ} \mathrm{C}$ (Additional file 13). Realtime reactions were carried out using SYBR green (Applied Biosystems, Foster City, CA, USA) on a ABI Prism 7000 Sequence Detection System (Applied Biosystems). Twenty microlitre reactions contained $2 \mu \mathrm{l}$ of cDNA and $0.4 \mu \mathrm{M}$ each primer. PCR amplification followed a two step cycling protocol; $10 \mathrm{~min}$ denaturation at $95^{\circ} \mathrm{C}$ followed by 40 cycles of $95^{\circ} \mathrm{C}$ for $15 \mathrm{~s}$ and $60^{\circ} \mathrm{C}$ for $1 \mathrm{~min}$. Melting curve analysis was conducted to confirm specific amplicon amplification. Patient reactions were performed in triplicate and standard curve points in duplicate. ABI Sequence Detection Software version 1.2 was used to determine sample Ct values, with the same threshold set for all reactions. Absolute copy number values calculated from standard curves were normalised to a calibrator cDNA sample (1 ng was used for RT-PCR) by calculating a ratio of the patient $18 \mathrm{~S} \mathrm{Ct}$ to that of the calibrator sample $18 \mathrm{~S}$ Ct. Differences between samples were analysed for $\log _{10}$ transformed data by Student's t-test, with significance set at $P<0.05$.

\section{Western blot analysis}

Whole tissue protein was isolated from the TRIreagent organic phase separated during RNA extraction following the manufacturer's instructions and reconstituting in 10 $M$ urea. Protein was quantified using the Bio-Rad Protein Assay (Bio-Rad, Regent Park, NSW, Australia) and 25 ng of total protein was resolved by $10 \%$ SDS-PAGE and transferred to a Hybond-C nitrocellulose membrane (Ammersham, North. Ryde, NSW, Australia). Membranes were blocked with Odyssey Blocking Buffer (LI-COR Biosciences, Lincoln, NE, USA) diluted 1:1 in TBS (50 mM TRIS pH 7.5, $150 \mathrm{mM} \mathrm{NaCl}$ ) for $45 \mathrm{~min}$. Antibodies were diluted $1: 1$ in blocking buffer with $0.1 \%$ Tween-20. Blocked membranes were probed with either mouse monoclonal anti-collagen type I (COL1, 1:100, Calbiochem, Alexandria, NSW, Australia) or goat anti-mouse CORS26/ C1qTNF3 (1:50, R\&D Systems, Minneapolis, MN, USA) and incubated overnight at $4{ }^{\circ} \mathrm{C}$. COL1-probed membranes were double probed with rabbit polyclonal antihuman retinol-binding protein (RBP4, 1:20000, DAKO, Botany, NSW, Australia) for $1 \mathrm{~h}$ at room temperature (RT). Membranes were washed three times in TBST (50
mM TRIS pH 7.5, $150 \mathrm{mM} \mathrm{NaCl,} \mathrm{0.1 \%} \mathrm{Tween-20)} \mathrm{follow-}$ ing primary antibody incubation. Antibody binding to double probed membranes was detected by infrared emission using goat anti-rabbit Alexa Flour 680 (1/20000, Molecular probes, Eugene, OR, USA) and goat anti-mouse IRDye 800 (1:15000, Rockland, Gilbertsville, PA, USA). Antibody binding to single probed membranes was detected with donkey anti-goat Alexa Fluor 680 (1:10000, Molecular Probes). Protein bands were detected and quantified using the Odyssey infrared imaging system (LICOR Biosciences). Double probed membranes were stripped with low pH stripping buffer ( $25 \mathrm{mM}$ glycineHCL pH 2, 1\% (w/v) SDS) for $30 \mathrm{~min}$ at RT, followed by washing in TBST. Stripped membranes were blocked in $5 \%$ skimmed milk in TBST for $30 \mathrm{~min}$. Membranes were probed with primary sheep anti-human glypican 3 (GPC3, 1:2000, R\&D Systems), followed by rabbit antisheep horseradish peroxidase-conjugated antibody (1:2000, Chemicon) and Immobilon Western Substrate (Millipore, North Ryde NSW, Australia). Antibodies for GPC3 detection were diluted in 5\% skimmed milk in TBST and incubated for $1 \mathrm{~h}$ at RT. For densitometry, GPC3 blots were scanned using the Odyssey imaging system (LICOR Biosciences).

\section{Immunofluorescence confocal microscopy}

Fixed and decalcified specimens were dehydrated through a graded ethanol series and embedded in paraffin. Sections were cut to $3 \mu \mathrm{m}$ thickness, mounted on 3-aminotriethoxysilane (APES)-coated slides and incubated for 16 $\mathrm{h}$ at $60^{\circ} \mathrm{C}$, followed by $7 \mathrm{~h}$ at $37^{\circ} \mathrm{C}$. Sections were deparaffinised and rehydrated in distilled $\mathrm{H}_{2} \mathrm{O}$ for $5 \mathrm{~min}$. Antigen retrieval was carried out using TEG buffer (TRISEGTA, pH 9.0) for RBP4 and COLX and TRIS-HCl buffer ( $\mathrm{pH}$ 1.0) for GPC3. All sections were incubated at 60$70^{\circ} \mathrm{C}$ overnight with constant stirring. Slides were cooled and washed in $1 \times$ PBS ( $\mathrm{pH} 7.4$ ) before incubating in blocking buffer $(0.3 \%$ casein, $0.1 \%$ Tween- 20 , in $1 \times$ PBS $\mathrm{pH} 7.4$ ) for 15 min. Rabbit polyclonal anti-human RBP4 (1:2000, DAKO), sheep anti-human GPC3 (1:50, R\&D Systems), and mouse monoclonal anti-collagen type $\mathrm{X}$ (COLX, 1:500, Sigma-Aldrich, Castle Hill, NSW, Australia) primary antibodies were incubated for $1 \mathrm{~h}$, followed by washing in $1 \times$ PBS and Tween 20 (0.1\%). Sections were incubated with corresponding secondary antibodies (goat anti-rabbit Alexa Fluor 488, donkey antisheep Alexa Fluor 488, goat anti-mouse Alexa Flour 488) for $1 \mathrm{~h}$ at RT followed by washing. All antibodies were diluted in $1 \times$ PBS. Sections were coverslipped using ProLong Gold antifade (Invitrogen) and viewed with a Leica TCS 4D confocal laser scanning microscope (Leica Laser Technology, Heidelberg, Germany). Secondary antibodies was excitated with a 488-nm laser and fluorescent light detected using a FITC band pass 520-560 nm barrier filter. The controls were prepared in the absence of the primary 
and the secondary antibodies, and with both antibodies but without antigen retrieval, and were negative in all cases.

\section{Histology and cartilage detection}

Decalcified formalin fixed specimens were sectioned (3 $\mu \mathrm{m})$, mounted onto APES-coated slides, and incubated at $60^{\circ} \mathrm{C}$ for $16 \mathrm{~h}$. Deparaffinised and rehydrated sections were stained with 1\% Alcian blue in 3\% aqueous acetic acid ( $\mathrm{pH} 2.5$ ) to detect the presence of cartilage, or hematoxylin and eosin for tissue structure, and mounted in Depex (Sigma-Aldrich). Sections were imaged using a brightfield microscope (Carl Zeiss Jena, Jena, Germany) equipped with a DFC480 digital camera (Leica Microsystems).

\section{Authors' contributions}

AKC performed RNA and protein isolation and quantification, RNA processing and microarray scanning and data mining, realtime quantitative RT-PCR and Western blot validation experiments, confocal immunofluorescence and histological analysis of suture tissues, and drafted the paper. Immunofluorescence and histological stainings were reviewed and discussed by AKC, IH, PA, and BP. PJA collected the suture samples and performed decalcification and fixation of specimens. CRW coordinated microarray quality control, data mining, and statistical analysis of quantitative RT-PCR validation experiments. BP assisted with drafting of the paper. AKC, AVD, BP, PA, PM, and $\mathrm{IH}$ participated in study's design and coordination. All authors have reviewed the manuscript. BP, IH, and $\mathrm{AKC}$ were the final editors of the manuscript.

\section{Additional material}

\section{Additional file 1}

Microarray quality control RNA digestion plot. RNA digestion plot, for the 16 RNA samples hybridised to Affymetrix Human expression U133A 2.0 GeneChip microarrays. RNA digestion plot compares expression intensity for all probes which bind sequences in order of $5^{\prime}$ to 3 ' along a transcript, for all probe sets on the GeneChip.

Click here for file

[http://www.biomedcentral.com/content/supplementary/1471-

2164-8-458-S1.pdf]

\section{Additional file 2}

Microarray quality control NUSE box plots. Normalised unscaled standard error (NUSE) box blots for the 16 RNA samples hybridised to Affymetrix Human expression U133A 2.0 GeneChip microarrays. NUSE box plot shows a ratio of the NUSE for each probe set compared to a median value of the NUSEs across all arrays.

Click here for file

[http://www.biomedcentral.com/content/supplementary/14712164-8-458-S2.pdf]

\section{Additional file 3}

Microarray quality control Mbox plots. Mbox plots for the 16 RNA samples hybridised to Affymetrix Human expression U133A 2.0 GeneChip microarrays. $M$ box plot shows the range of fold change $(M)$ for each probe set expressed by one sample compared to the mean expression of that probe set across all samples analysed.

Click here for file

[http://www.biomedcentral.com/content/supplementary/1471-

2164-8-458-S3.pdf]

\section{Additional file 4}

Hierarchical cluster based on whole genome expression. Diana divisive hierarchical cluster of the 16 tissue samples analysed based on the expression intensity of all probe sets on the microarray.

Click here for file

[http://www.biomedcentral.com/content/supplementary/14712164-8-458-S4.pdf]

\section{Additional file 5}

Genes with $>2$-fold differential expression between sutures. List of the top 829 differentially expressed genes with $>2$-fold differential expression between fusing/fused and unfused suture tissue. A positive value indicates higher levels in fused sutures and a negative value indicates higher expression in unfused sutures.

Click here for file

[http://www.biomedcentral.com/content/supplementary/1471-

2164-8-458-S5.xls]

\section{Additional file 6}

Enrichments plots generated by GSEA analysis for selected significantly correlated datasets. The colour bar depicts phenotype correlation based on ranking metric scores. Red indicates those genes with increased expression in fused sutures and blue indicates those genes with increased expression in unfused sutures. Black bars represent genes ordered by their ranking within the 2-fold differentially expressed gene list between fused/fusing and unfused sutures.

Click here for file

[http://www.biomedcentral.com/content/supplementary/14712164-8-458-S6.pdf]

\section{Additional file 7}

$H \& E$ analysis of suture tissue. A large number of white blood cells were observed in the calvarial tissue. The majority of cells appear as lymphocytes $\left({ }^{*}\right)$.

Click here for file

[http://www.biomedcentral.com/content/supplementary/1471-

2164-8-458-S7.pdf]

\section{Additional file 8}

Genes identified to be differentially expressed $(\mathrm{P}<0.01)$ by matched pairs analysis between unfused coronal and sagittal sutures. A positive value indicates higher expression levels in coronal sutures and a negative value indicates higher expression in sagittal sutures.

Click here for file

[http://www.biomedcentral.com/content/supplementary/14712164-8-458-S8.xls] 


\section{Additional file 9}

Genes identified to be differentially expressed $(\mathrm{P}<0.01)$ by matched pairs analysis between unfused lambdoid and sagittal sutures. A positive value indicates higher expression levels in lambdoid sutures and a negative value indicates higher expression in sagittal sutures.

Click here for file

[http://www.biomedcentral.com/content/supplementary/14712164-8-458-S9.xls]

\section{Additional file 10}

Genes identified to be differentially expressed $(\mathrm{P}<0.01)$ by matched pairs analysis between unfused coronal and lambdoid sutures. A positive value indicates higher expression levels in coronal sutures and a negative value indicates higher expression in lambdoid sutures.

Click here for file

[http://www.biomedcentral.com/content/supplementary/14712164-8-458-S10.xls]

\section{Additional file 11}

Syndromic and non-syndromic sutures are not significantly different. $P_{-}$ values from Student's $t$-test comparing gene expression between syndromic and non-syndromic samples from for each stage of development. Samples from different suture sites were combined for analysis.

Click here for file

[http://www.biomedcentral.com/content/supplementary/14712164-8-458-S11.xls]

\section{Additional file 12}

qRT-PCR results for the additional genes not shown in Figure 6A. The long isoform of C1QTNF3 had limited to no differential expression between unfused, fusing, and fused suture from the different sites and was therefore not the highly significantly differentially expressed isoform. COL8A2 and COL3A1 had increased expression in unfused compared to fused sutures, except in the sagittal suture.

Click here for file

[http://www.biomedcentral.com/content/supplementary/14712164-8-458-S12.pdf

\section{Additional file 13}

Primers used for realtime $q R T-P C R$.

Click here for file

[http://www.biomedcentral.com/content/supplementary/14712164-8-458-S13.xls]

\section{Acknowledgements}

We thank the families for their cooperation and interest; Prof. David J David who offered his patients to be included in this study; Dr Christina Theodoropolous for expert technical assistance with confocal microscopy; and $\mathrm{Dr}$ Peter Self for conducting MicroCT analyses. Mutation detection was carried out by the South Eastern Area Laboratory Service, Molecular and Cytogenetics laboratory, Prince of Wales Hospital, NSW. This work was supported by the Cooperative Research Centre for Diagnostics, Friends of the Australian Craniofacial Foundation, and the Australian Craniofacial Institute.

\section{References}

I. Opperman LA: Cranial sutures as intramembranous bone growth sites. Dev Dyn 2000, 21 9:472-485.
2. Furtwangler JA, Hall SH, Koskinen-Moffett LK: Sutural morphogenesis in the mouse calvaria: the role of apoptosis. Acta Anat (Basel) 1985, I 24:74-80.

3. Wilkie AO: Epidemiology and genetics of craniosynostosis. Am J Med Genet 2000, 90:82-84.

4. Yip JE, Kokich VG, Shepard TH: The effect of high doses of retinoic acid on prenatal craniofacial development in Macaca nemestrina. Teratology 1980, 21:29-38.

5. Cohen MM Jr.: Sutural biology and the correlates of craniosynostosis. Am J Med Genet 1993, 47:581-616.

6. Muenke M, Wilkie AO: Craniosynostosis Syndromes. In The Metabolic and Molecular Bases of Inherited Disease Volume 3. 8th edition. Edited by: Sciver CR, Beaudet AL, Sly WS, Valle D, Childs B and Vogelstein B. New York, McGraw-Hill; 2000:6I I7-6I46.

7. Rice DP: Craniofacial anomalies: from development to molecular pathogenesis. Curr Mol Med 2005, 5:699-722.

8. Roth DA, Longaker MT, McCarthy JG, Rosen DM, McMullen HF, Levine JP, Sung J, Gold LI: Studies in cranial suture biology: Part I. Increased immunoreactivity for TGF-beta isoforms (beta I, beta 2 , and beta 3 ) during rat cranial suture fusion. I Bone Miner Res 1997, I 2:3। I-32।.

9. Opperman LA, Chhabra A, Cho RW, Ogle RC: Cranial suture obliteration is induced by removal of transforming growth factor (TGF)-beta 3 activity and prevented by removal of TGF-beta 2 activity from fetal rat calvaria in vitro. J Craniofac Genet Dev Biol 1999, 19:164-I73.

10. Lee MH, Kim YJ, Kim HJ, Park HD, Kang AR, Kyung HM, Sung JH, Wozney JM, Ryoo HM: BMP-2-induced Runx2 expression is mediated by DIx5, and TGF-beta I opposes the BMP-2induced osteoblast differentiation by suppression of DIx 5 expression. J Biol Chem 2003, 278:34387-34394.

II. Kim HJ, Rice DP, Kettunen PJ, Thesleff I: FGF-, BMP- and Shhmediated signalling pathways in the regulation of cranial suture morphogenesis and calvarial bone development. Development 1998, I 25: I24I-I25I.

12. Jiang X, Iseki S, Maxson RE, Sucov HM, Morriss-Kay GM: Tissue origins and interactions in the mammalian skull vault. Dev Biol 2002, 241: 106-116.

13. Couly GF, Coltey PM, Le Douarin NM: The triple origin of skull in higher vertebrates: a study in quail-chick chimeras. Development 1993, II 7:409-429.

14. Morriss-Kay GM, Wilkie AO: Growth of the normal skull vault and its alteration in craniosynostosis: insights from human genetics and experimental studies. J Anat 2005, 207:637-653.

15. Spector JA, Mehrara BJ, Greenwald JA, Saadeh PB, Steinbrech DS, Smith LP, Longaker MT: A molecular analysis of the isolated rat posterior frontal and sagittal sutures: differences in gene expression. Plast Reconstr Surg 2000, 106:852-86I; discussion 862867.

16. Song HM, Sahar DE, Fong KD, Nacamuli RP, Fang TD, Mathy JA, Aalami OO, Warren SM, Longaker MT: In vitro murine posterior frontal suture fate is age-dependent: implications for cranial suture biology. Plast Reconstr Surg 2004, I | 3: I 1 92-1204.

17. Nacamuli RP, Fong KD, Warren SM, Fang TD, Song HM, Helms JA, Longaker MT: Markers of osteoblast differentiation in fusing and nonfusing cranial sutures. Plast Reconstr Surg 2003, I I 2: 1328-1335

18. Mehrara BJ, Mackool RJ, McCarthy JG, Gittes GK, Longaker MT: Immunolocalization of basic fibroblast growth factor and fibroblast growth factor receptor- $I$ and receptor-2 in rat cranial sutures. Plast Reconstr Surg 1998, 102:1805-1817; discus- sion
$1818-1820$

19. Gosain AK, Recinos RF, Agresti M, Khanna AK: TGF-beta I, FGF2 , and receptor mRNA expression in suture mesenchyme and dura versus underlying brain in fusing and nonfusing mouse cranial sutures. Plast Reconstr Surg 2004, I I 3:1675-1684.

20. Bradley JP, Han VK, Roth DA, Levine JP, McCarthy JG, Longaker MT: Increased IGF-I and IGF-II mRNA and IGF-I peptide in fusing rat cranial sutures suggest evidence for a paracrine role of insulin-like growth factors in suture fusion. Plast Reconstr Surg 1999, 104:129-138.

21. Zhou YX, Xu X, Chen L, Li C, Brodie SG, Deng CX: A Pro250Arg substitution in mouse Fgfrl causes increased expression of $\mathrm{Cbfal}$ and premature fusion of calvarial sutures. Hum Mol Genet 2000, 9:200I-2008. 
22. Marie PJ, Coffin JD, Hurley MM: FGF and FGFR signalling in chondrodysplasias and craniosynostosis. J Cell Biochem 2005 , 96:888-896.

23. Jabs EW, Li X, Scott AF, Meyers G, Chen W, Eccles M, Mao JI, Charnas LR, Jackson CE, Jaye M: Jackson-Weiss and Crouzon syndromes are allelic with mutations in fibroblast growth factor receptor 2. Nat Genet 1994, 8:275-279.

24. Iseki S, Wilkie AO, Morriss-Kay GM: Fgfr I and Fgfr2 have distinct differentiation- and proliferation-related roles in the developing mouse skull vault. Development I999, I 26:56 I I-5620.

25. Rice DP, Aberg T, Chan Y, Tang Z, Kettunen PJ, Pakarinen L, Maxson RE, Thesleff I: Integration of FGF and TWIST in calvarial bone and suture development. Development 2000, I 27:1845-1855.

26. Lyn Chong S, Mitchell R, Moursi AM, Winnard P, Losken HW, Bradley J, Ozerdem OR, Azari K, Acarturk O, Opperman LA, Siegel MI, Mooney MP: Rescue of coronal suture fusion using transforming growth factor-beta 3 (Tgf-beta 3 ) in rabbits with delayedonset craniosynostosis. Anat $\operatorname{Rec} 2003$, 274A:962-97I.

27. Opperman LA, Nolen AA, Ogle RC: TGF-beta I, TGF-beta 2, and TGF-beta 3 exhibit distinct patterns of expression during cranial suture formation and obliteration in vivo and in vitro. J Bone Miner Res 1997, I 2:301-3 I0.

28. Chien HH, Lin WL, Cho MI: Down-regulation of osteoblastic cell differentiation by epidermal growth factor receptor. Calcif Tissue Int 2000, 67:14I-I50.

29. Coussens AK, Hughes IP, Wilkinson CR, Morris CP, Anderson PJ, Powell $B C$, van Daal A: Identification of genes differentially expressed by prematurely fused human sutures using a novel in vivo - in vitro approach. Differentiation 2007 in press. [Epub ahead of print]

30. Walsh MC, Kim N, Kadono Y, Rho J, Lee SY, Lorenzo J, Choi Y: Osteoimmunology: interplay between the immune system and bone metabolism. Annu Rev Immunol 2006, 24:33-63.

31. Marriott I: Osteoblast responses to bacterial pathogens: a previously unappreciated role for bone-forming cells in host defense and disease progression. Immunol Res 2004, 30:291-308.

32. Merrill AE, Bochukova EG, Brugger SM, Ishii M, Pilz DT, Wall SA Lyons KM, Wilkie AO, Maxson RE Jr.: Cell mixing at a neural crest-mesoderm boundary and deficient ephrin-Eph signaling in the pathogenesis of craniosynostosis. Hum Mol Genet 2006, I 5:1319-1328.

33. Twigg SR, Kan R, Babbs C, Bochukova EG, Robertson SP, Wall SA, Morriss-Kay GM, Wilkie AO: Mutations of ephrin-BI (EFNBI), a marker of tissue boundary formation, cause craniofrontonasal syndrome. Proc Natl Acad Sci U S A 2004, I 0 I:8652-8657.

34. Wilda M, Bachner D, Just W, Geerkens C, Kraus P, Vogel W, Hameister $\mathrm{H}$ : A comparison of the expression pattern of five genes of the family of small leucine-rich proteoglycans during mouse development. J Bone Miner Res 2000, I 5:2 187-2196.

35. Svensson L, Narlid I, Oldberg A: Fibromodulin and lumican bind to the same region on collagen type I fibrils. FEBS Lett 2000 , 470: $178-182$.

36. Hildebrand A, Romaris M, Rasmussen LM, Heinegard D, Twardzik DR, Border WA, Ruoslahti E: Interaction of the small interstitial proteoglycans biglycan, decorin and fibromodulin with transforming growth factor beta. Biochem J 1994, 302 (Pt 2):527-534.

37. Li G, Bunn JR, Mushipe MT, He Q, Chen X: Effects of pleiotrophin (PTN) over-expression on mouse long bone development, fracture healing and bone repair. Calcif Tissue Int 2005, 76:299-306.

38. Oshima A, Tanabe H, Yan T, Lowe GN, Glackin CA, Kudo A: A novel mechanism for the regulation of osteoblast differentiation: transcription of periostin, a member of the fasciclin I family, is regulated by the bHLH transcription factor, twist. J Cell Biochem 2002, 86:792-804.

39. Krishnan V, Bryant HU, Macdougald OA: Regulation of bone mass by Wnt signaling. J Clin Invest 2006, I I 6: I 202-I 209.

40. Vaes BL, Dechering KJ, van Someren EP, Hendriks JM, van de Ven CJ, Feijen A, Mummery CL, Reinders MJ, Olijve W, van Zoelen EJ, Steegenga WT: Microarray analysis reveals expression regulation of Wnt antagonists in differentiating osteoblasts. Bone 2005, 36:803-8II.

4I. Linsenmayer TF, Eavey RD, Schmid TM: Type $X$ collagen: a hypertrophic cartilage-specific molecule. Pathol Immunopathol Res 1988, 7:14-19.
42. Gong Y, Slee RB, Fukai N, Rawadi G, Roman-Roman S, Reginato AM, Wang H, Cundy T, Glorieux FH, Lev D, Zacharin M, Oexle K, Marcelino J, Suwairi W, Heeger S, Sabatakos G, Apte S, Adkins WN, Allgrove J, Arslan-Kirchner M, Batch JA, Beighton P, Black GC, Boles RG, Boon LM, Borrone C, Brunner HG, Carle GF, Dallapiccola B, De Paepe A, Floege B, Halfhide ML, Hall B, Hennekam RC, Hirose T, Jans A, Juppner H, Kim CA, Keppler-Noreuil K, Kohlschuetter A, LaCombe D, Lambert M, Lemyre E, Letteboer T, Peltonen L, Ramesar RS, Romanengo M, Somer H, Steichen-Gersdorf E, Steinmann B, Sullivan B, Superti-Furga A, Swoboda W, van den Boogaard MJ, Van Hul W, Vikkula M, Votruba M, Zabel B, Garcia T, Baron R, Olsen BR, Warman ML: LDL receptor-related protein 5 (LRP5) affects bone accrual and eye development. Cell 200I, 107:5I3-523.

43. Mansukhani A, Ambrosetti D, Holmes G, Cornivelli L, Basilico C: Sox2 induction by FGF and FGFR2 activating mutations inhibits Wnt signaling and osteoblast differentiation. J Cell Biol 2005, 168:1065-1076.

44. Quadro L, Blaner WS, Salchow DJ, Vogel S, Piantedosi R, Gouras P Freeman S, Cosma MP, Colantuoni V, Gottesman ME: Impaired retinal function and vitamin $A$ availability in mice lacking retinol-binding protein. Embo J 1999, I 8:4633-4644.

45. Mukhopadhyay P, Greene RM, Zacharias W, Weinrich MC, Singh S, Young WW Jr., Pisano MM: Developmental gene expression profiling of mammalian, fetal orofacial tissue. Birth Defects Res A Clin Mol Teratol 2004, 70:912-926.

46. Kawashima-Ohya Y, Kuruta Y, Yan W, Kawamoto T, Noshiro M, Kato $Y$ : Retinol-binding protein is produced by rabbit chondrocytes and responds to parathyroid hormone (PTH)/ PTH-related peptide-cyclic adenosine monophosphate pathway. Endocrinology 1999, I40:1075-108I.

47. Komatsu Y, Watakabe A, Hashikawa T, Tochitani S, Yamamori T: Retinol-binding protein gene is highly expressed in higherorder association areas of the primate neocortex. Cereb Cortex 2005, 15:96-108.

48. Makover A, Soprano DR, Wyatt ML, Goodman DS: Localization of retinol-binding protein messenger RNA in the rat kidney and in perinephric fat tissue. J Lipid Res 1989, 30: I7I-I80.

49. Quadro L, Blaner WS, Hamberger L, Van Gelder RN, Vogel S, Piantedosi R, Gouras P, Colantuoni V, Gottesman ME: Muscle expression of human retinol-binding protein (RBP). Suppression of the visual defect of RBP knockout mice. J Biol Chem 2002, 277:30191-30197.

50. Quadro L, Blaner WS, Hamberger L, Novikoff PM, Vogel S, Piantedosi $\mathrm{R}$, Gottesman ME, Colantuoni V: The role of extrahepatic retinol binding protein in the mobilization of retinoid stores. J Lipid Res 2004, 45:1975-1982.

5I. Young DL, Schneider RA, Hu D, Helms JA: Genetic and teratogenic approaches to craniofacial development. Crit Rev Oral Biol Med 2000, I I :304-3 I 7.

52. Morriss-Kay G: Retinoic acid and craniofacial development: molecules and morphogenesis. Bioessays 1993, I5:9-15.

53. Park CK, Ishimi Y, Ohmura M, Yamaguchi M, Ikegami S: Vitamin A and carotenoids stimulate differentiation of mouse osteoblastic cells. J Nutr Sci Vitaminol (Tokyo) 1997, 43:28I-296.

54. Jimenez MJ, Balbin M, Alvarez J, Komori T, Bianco P, Holmbeck K, Birkedal-Hansen $\mathrm{H}$, Lopez JM, Lopez-Otin C: A regulatory cascade involving retinoic acid, Cbfal, and matrix metalloproteinases is coupled to the development of a process of perichondrial invasion and osteogenic differentiation during bone formation. J Cell Biol 200I, I 55: I 333-I344.

55. Gazit D, Ebner R, Kahn AJ, Derynck R: Modulation of expression and cell surface binding of members of the transforming growth factor-beta superfamily during retinoic acid-induced osteoblastic differentiation of multipotential mesenchymal cells. Mol Endocrinol 1993, 7:189-198.

56. Song HM, Nacamuli RP, Xia W, Bari AS, Shi YY, Fang TD, Longaker MT: High-dose retinoic acid modulates rat calvarial osteoblast biology. J Cell Physiol 2005, 202:255-262.

57. Quadro L, Hamberger L, Gottesman ME, Wang F, Colantuoni V, Blaner WS, Mendelsohn CL: Pathways of vitamin A delivery to the embryo: insights from a new tunable model of embryonic vitamin A deficiency. Endocrinology 2005, I 46:4479-4490.

58. Gardner JS, Guyard-Boileau B, Alderman BW, Fernbach SK, Greene $C$, Mangione EJ: Maternal exposure to prescription and nonprescription pharmaceuticals or drugs of abuse and risk of craniosynostosis. Int J Epidemiol 1998, 27:64-67. 
59. Pilia G, Hughes-Benzie RM, MacKenzie A, Baybayan P, Chen EY, Huber R, Neri G, Cao A, Forabosco A, Schlessinger D: Mutations in GPC3, a glypican gene, cause the Simpson-Golabi-Behmel overgrowth syndrome. Nat Genet 1996, 12:24I-247.

60. De Cat B, Muyldermans SY, Coomans C, Degeest G, Vanderschueren B, Creemers ], Biemar F, Peers B, David G: Processing by proprotein convertases is required for glypican-3 modulation of cell survival, Wnt signaling, and gastrulation movements. J Cell Biol 2003, I 63:625-635.

6I. Midorikawa Y, Ishikawa S, Iwanari H, Imamura T, Sakamoto H, Miyazono K, Kodama T, Makuuchi M, Aburatani H: Glypican-3, overexpressed in hepatocellular carcinoma, modulates FGF2 and BMP-7 signaling. Int J Cancer 2003, 103:455-465.

62. Paine-Saunders S, Viviano BL, Zupicich J, Skarnes WC, Saunders S: glypican-3 controls cellular responses to Bmp4 in limb patterning and skeletal development. Dev Biol 2000, 225: I79-187.

63. Song HH, Shi $W$, Xiang YY, Filmus J: The loss of glypican-3 induces alterations in Wnt signaling. J Biol Chem 2005 , 280:21 16-2125.

64. Maeda T, Jikko A, Abe M, Yokohama-Tamaki T, Akiyama H, Furukawa S, Takigawa M, Wakisaka S: Cartducin, a paralog of Acrp30/adiponectin, is induced during chondrogenic differentiation and promotes proliferation of chondrogenic precursors and chondrocytes. J Cell Physiol 2006, 206:537-544.

65. Akiyama H, Furukawa S, Wakisaka S, Maeda T: CTRP3/cartducin promotes proliferation and migration of endothelial cells. Mol Cell Biochem 2007.

66. Hinton DR, Becker LE, Muakkassa KF, Hoffman HJ: Lambdoid synostosis. Part I: The lambdoid suture: Normal development and pathology of "synostosis". J Neurosurg 1984, 61:333-339.

67. Pritchard J, Scott JH, Girgis FG: The structure and development of cranial and facial sutures. Journal of anatomy 1956, 90:73-86.

68. Wang Y, Xiao R, Yang F, Karim BO, lacovelli AJ, Cai J, Lerner CP, Richtsmeier JT, Leszl JM, Hill CA, Yu K, Ornitz DM, Elisseeff J, Huso $\mathrm{DL}$, Jabs EW: Abnormalities in cartilage and bone development in the Apert syndrome FGFR2(+/S252W) mouse. Development 2005, I 32:3537-3548.

69. Sahar DE, Longaker MT, Quarto N: Sox9 neural crest determinant gene controls patterning and closure of the posterior frontal cranial suture. Dev Biol 2005, 280:344-36I.

70. Nah HD, Pacifici M, Gerstenfeld LC, Adams SL, Kirsch T: Transient chondrogenic phase in the intramembranous pathway during normal skeletal development. J Bone Miner Res 2000, I 5:522-533.

7I. Kim HJ, Lee MH, Park HS, Park MH, Lee SW, Kim SY, Choi JY, Shin $\mathrm{HI}$, Ryoo HM: Erk pathway and activator protein I play crucial roles in FGF2-stimulated premature cranial suture closure. Dev Dyn 2003, 227:335-346

72. Anderson PJ, Cox TC, Roscioli T, Elakis G, Smithers L, David DJ, Pow ell BC: Somatic FGFR and TWIST mutations are not a common cause of isolated non-syndromic single suture craniosynostosis. J Craniofac Surg 2007, I 8:312-314.

73. Anderson PJ, Netherway DJ, David DJ, Self P: Scanning electron microscope and micro-CT evaluation of cranial sutures in health and disease. J Craniofac Surg 2006, I 7:909-919.

74. Naderi A, Ahmed AA, Barbosa-Morais NL, Aparicio S, Brenton JD, Caldas C: Expression microarray reproducibility is improved by optimising purification steps in RNA amplification and labelling. BMC Genomics 2004, 5:9.

75. Gentleman RC, Carey VJ, Bates DM, Bolstad B, Dettling M, Dudoit S, Ellis B, Gautier L, Ge Y, Gentry J, Hornik K, Hothorn T, Huber W lacus S, Irizarry R, Leisch F, Li C, Maechler M, Rossini AJ, Sawitzki G, Smith C, Smyth G, Tierney L, Yang JY, Zhang J: Bioconductor: open software development for computational biology and bioinformatics. Genome Biol 2004, 5:R80.

76. Bioconductor: open source software for bioinformatics [http://www.bioconductor.org]

77. Bolstad BM: Low Level Analysis of High-density Oligonucleotide Array Data: Background, Normalization and Summarization. Phd Thesis; Department of Biostatistics 2004 [http:// bmbolstad.com/Dissertation/Bolstad 2004 Dissertation.pdf]. Berkeley, University of California

78. Wu Z, Irizarry R, Gentleman R, Murillo F, Spencer F: A model based background adjustment for oligonucleotide expression arrays. Journal of the American Statistical Association 2004, 99:909-917.
79. Smyth GK: Linear models and empirical Bayes methods for assessing differential expression in microarray experiments. Statistical Applications in Genetics and Molecular Biology 2004, 3:Article 3.

80. Benjamini $\mathrm{Y}$, Hochberg $\mathrm{Y}$ : Controlling the false discovery rate: a practical and powerful appraoch to multiple testing. I $R$ Statis Soc 1995, B 57:289-300.

8I. Zhang B, Schmoyer D, Kirov S, Snoddy J: GOTree Machine (GOTM): a web-based platform for interpreting sets of interesting genes using Gene Ontology hierarchies. BMC Bioinformatics 2004, 5: 16 .

82. Gene Ontology Tree Machine [http://bioinfo.vanderbilt.edu/ gotm/]

83. Subramanian A, Tamayo P, Mootha VK, Mukherjee S, Ebert BL, Gillette MA, Paulovich A, Pomeroy SL, Golub TR, Lander ES, Mesirov JP: Gene set enrichment analysis: a knowledge-based approach for interpreting genome-wide expression profiles. Proc Nat Acad Sci U S A 2005, I 02: I5545-I5550.

84. Gene Set Enrichment Analysis [http://www.broad.mit.edu/gsea]
Publish with Biomed Central and every scientist can read your work free of charge

"BioMed Central will be the most significant development for disseminating the results of biomedical research in our lifetime. "

Sir Paul Nurse, Cancer Research UK

Your research papers will be:

- available free of charge to the entire biomedical community

- peer reviewed and published immediately upon acceptance

- cited in PubMed and archived on PubMed Central

- yours - you keep the copyright
BioMedcentral 